\title{
Externally Forced and Internal Variability in Ensemble Climate Simulations of the Maunder Minimum
}

\author{
Masakazu Yoshimori, ${ }^{*}$ Thomas F. Stocker, Christoph C. Raible, and Manuel Renold \\ Climate and Environmental Physics, Physics Institute, University of Bern, Bern, Switzerland
}

(Manuscript received 2 December 2004, in final form 21 April 2005)

\begin{abstract}
The response of the climate system to natural, external forcing during the Maunder Minimum (ca. A.D. 1645-1715) is investigated using a comprehensive climate model. An ensemble of six transient simulations is produced in order to examine the relative importance of externally forced and internally generated variability. The simulated annual Northern Hemisphere and zonal-mean near-surface air temperature agree well with proxy-based reconstructions on decadal time scales. A mean cooling signal during the Maunder Minimum is masked by the internal unforced variability in some regions such as Alaska, Greenland, and northern Europe. In general, temperature exhibits a better signal-to-noise ratio than precipitation. Mean salinity changes are found in basin averages. The model also shows clear response patterns to volcanic eruptions. In particular, volcanic forcing is projected onto the winter North Atlantic Oscillation index following the eruptions. It is demonstrated that the significant spread of ensemble members is possible even on multidecadal time scales, which has an important implication in coordinating comparisons between model simulations and regional reconstructions.
\end{abstract}

\section{Introduction}

There are several reasons for studying climate variability in the last millennium even though only proxybased reconstructions are available during most of the period (Jones et al. 2001; Bradley et al. 2003; Moberg et al. 2005). Climate change in the last decades is described with a long-term perspective, and its relevance to anthropogenic forcing is inferred from reconstructions (Mann et al. 2003, and references therein) and tested by climate models. In addition, long-term records are necessary to obtain a robust picture of variability on decadal to centennial time scales. Climate during the preindustrial period is influenced mainly by natural, external forcing and little "contaminated" by various anthropogenic radiative forcing agents. The knowledge of the response pattern and natural variabil-

\footnotetext{
* Current affiliation: Center for Environmental Prediction, Rutgers-The State University of New Jersey, New Brunswick, New Jersey.

Corresponding author address: Masakazu Yoshimori, Center for Environmental Prediction, Rutgers-The State University of New Jersey, 14 College Farm Road, New Brunswick, NJ 089018551.

E-mail: masa@cep.rutgers.edu
}

ity will lead to a better understanding of the climate system and contribute to the attribution of the recent climate change.

Evolution of climate in the past and the future may be viewed as one trajectory in phase space whereby its structure is determined by physical principles, and its exact path is subject to stochasticity (Lorenz 1963). From this point of view, analyses using observational records and reconstructions suffer from stochastic uncertainty as they represent only a single realization. This uncertainty is, indeed, taken into account in the detection of climate change (Mitchell et al. 2001) and the Bayesian estimate of model and forcing parameters (Forest et al. 2002; Knutti et al. 2002). In the framework of climate modeling, the stochastic uncertainty corresponds to the variability that is present without timevarying external forcing. On the other hand, Palmer $(1998,1999)$ formulated the fundamental paradigm that a weak, externally forced signal is captured as changes in probability density functions of the internal noise in the Lorenz model. In consequence, it may be difficult to distinguish externally forced and internal variabilities. Hence there is no direct way to verify the internal variability generated by models. Nevertheless, some confidence in model viability in simulating realistic variability may be gained by examining the natural variability. 
There have been a number of studies that focus on the comparison of time series of global variables over the last centuries between model simulations and reconstructions (e.g., Robock 1978a,b; Free and Robock 1999; Crowley 2000; Bertrand et al. 2002; Bauer et al. 2003; Gerber et al. 2003). Usually, these studies are conducted using relatively simple models owing to the required length of the integration, but they are useful in addressing the evolution of global or hemispheric variables. Also, such computationally efficient models are able to perform a large number of ensemble simulations and hence to incorporate forcing uncertainties. To extend these studies further to regional scales (Luterbacher et al. 2002, 2004), comprehensive climate models are, however, necessary. The possible steps would be to 1) extract the externally forced signal from ensemble simulations, 2) compare with reconstructions, and 3) understand the underlying mechanisms. In the present study, we focus primarily on the first step in the context of all three being a long-term goal. Coupled GCMs are computationally expensive, and often only a single simulation is conducted (Zorita et al. 2004). To acquire a reasonable size of ensemble members, we restrict our time window to the relatively short period of the Maunder Minimum.

The Maunder Minimum is characterized by a globally distinct and prolonged cold period of a few decades in the late seventeenth/early eighteenth century (Eddy 1976). It is well known that the sunspot number, a proxy of solar activity, was significantly low during this period. In a long-term perspective, it is sometimes described as a climax of the Little Ice Age from which time the earth gradually warms up until the warming is further accelerated by anthropogenic greenhouse gases. Concurrent volcanic eruptions during the Maunder Minimum and the presence of the internal climate variability complicate the picture. The relative importance and combination of these effects are not fully understood. We address issues on extracting the externally forced signal during this period.

The outline of the rest of this paper is as follows. In the next section we briefly describe the model. Section 3 presents the experimental design, the results of which are presented in section 4 , and the discussion follows in section 5. We conclude with a summary in section 6 .

\section{Model description}

The model used in this study is the Community Climate System Model (CCSM) version 2.0.1 developed by the National Center for Atmospheric Research (NCAR; Kiehl and Gent 2004). The model consists of atmosphere, ocean, land surface, and sea ice components, and they are coupled without flux corrections.
We choose the lower-resolution setting from the two different resolutions of the model officially supported by NCAR, based on the available computational resources.

The atmospheric component is a primitive equation model in which the spectral transform method, with triangular truncation at zonal wavenumber 31 , is employed to represent horizontal variations. This yields an approximate resolution of $3.75^{\circ}$ in both latitude and longitude. For vertical discretization, a finite-difference formulation on a hybrid coordinate system is used. There are 26 unevenly spaced sigma-pressure levels between the surface and $2.9 \mathrm{hPa}$ : about 11 to 16 levels from the surface up to the tropopause. The land surface component shares the same horizontal resolution with the associated Gaussian grid of the atmospheric component. There are 10 soil layers, in which temperature and moisture (water and ice) are computed, and thickness-dependent multiple snow layers with a maximum of 5. A grid box may fractionally contain up to 5 different surface types (glacier, lake, wetland, urban, and vegetated) with 4 to 16 different vegetation types. River routing is predetermined based on topography data.

The ocean component is a primitive equation model in which the finite-difference method is employed for the discretization. It has a longitudinal resolution of $\sim 3.6^{\circ}$ and variable latitudinal resolutions, which are refined in the Tropics up to $\sim 0.9^{\circ}$ with an average of $\sim 1.8^{\circ}$. Numerical poles are located in Greenland and Antarctica. There are 25 unevenly spaced depth levels between the surface and $5000 \mathrm{~m}$ in depth: 5 and 13 levels from the surface down to 100 and $1000 \mathrm{~m}$, respectively. The sea ice component shares the same horizontal resolution as the ocean component. It includes multicategory ice thickness distribution, thermodynamics, and dynamics and employs the elastic-viscousplastic ice rheology.

The coupled model reproduces overall a realistic present-day climatology except that the Atlantic meridional overturning circulation is weak $[\sim 7 \mathrm{~Sv}(1 \mathrm{~Sv} \equiv$ $\left.10^{6} \mathrm{~m}^{3} \mathrm{~s}^{-1}\right)$ ]. This contributes to a large cold bias in northwestern Europe. More detailed descriptions of the model components are available online at the NCAR CCSM Web page (http://www.cgd.ucar.edu/ $\operatorname{csm} /)$.

\section{Experimental design}

We conduct four types of model simulations: a present-day control (hereafter CTRL), a steady Maunder Minimum (SMM), a transient Maunder Minimum (TMM), and a solar-forcing-only TMM (STMM) simulation. In the CTRL and SMM simulations, perpetual A.D. 1990 and 1640 forcings are applied, respectively (Table 1). 
TABLE 1. Forcing used in the CTRL and SMM simulations. The difference in radiative forcing between the two simulations is also presented. Radiative forcing due to greenhouse gases is calculated using the formula in Ramaswamy et al. (2001), which includes the effect of fast stratospheric adjustments. For the $\mathrm{CO}_{2}$, only the range of estimates yielded by the three different formulas is presented. TSI denotes the total solar irradiance. A planetary albedo of 0.3 is assumed in converting the TSI to the instantaneous radiative forcing.

\begin{tabular}{lccc}
\hline \hline $\begin{array}{c}\text { Radiative } \\
\text { forcing } \\
\text { agent }\end{array}$ & $\begin{array}{c}\text { CTRL } \\
\text { (A.D. 1990) }\end{array}$ & $\begin{array}{c}\text { SMM } \\
\text { (A.D. 1640) }\end{array}$ & $\begin{array}{c}\text { Difference } \\
\text { in radiative } \\
\text { forcing } \\
\left(\mathrm{W} \mathrm{m}^{-2}\right)\end{array}$ \\
\hline $\mathrm{TSI}$ & $1367.0 \mathrm{~W} \mathrm{~m}^{-2}$ & $1365.1 \mathrm{~W} \mathrm{~m}^{-2}$ & 0.33 \\
$\mathrm{CO}_{2}$ & $355 \mathrm{ppmv}$ & $276 \mathrm{ppmv}$ & $1.34-1.42$ \\
$\mathrm{CH}_{4}$ & $1714 \mathrm{ppbv}$ & $691 \mathrm{ppbv}$ & 0.47 \\
$\mathrm{~N}_{2} \mathrm{O}$ & $311 \mathrm{ppbv}$ & $270 \mathrm{ppbv}$ & 0.13 \\
$\mathrm{CFC}-11$ & $0.280 \mathrm{ppbv}$ & $0 \mathrm{ppbv}$ & 0.07 \\
$\mathrm{CFC}-12$ & $0.503 \mathrm{ppbv}$ & $0 \mathrm{ppbv}$ & 0.16 \\
& & & \\
Total & - & - & $2.51-2.58$ \\
\hline
\end{tabular}

In the CTRL simulation, the model is integrated for 270 years starting from the modern climate state based on observations. After about 100 years of integration, the model reaches a quasi-steady state, and we use the data of the last $76 \mathrm{yr}$ in our analysis. The $76 \mathrm{yr}$ correspond to the length of each TMM simulation (A.D. 1640-1715). Independent of this simulation, we also use model output from the CTRL simulation with the identical model except that the computation is made on a different computer (Linux PC cluster) in which the model is integrated for as much as 565 years (Renold et al. 2004). The data of the last $465 \mathrm{yr}$ are used in our analysis. (For clarity, we note that these data are used only in Figs. 2, 4, and 10 in which a longer control simulation is preferable.) Note also that there is no significant difference in the climatological mean state between the two CTRL simulations.

For the SMM simulation, we spin up the model, starting from the steady-state CTRL simulation with forcing conditions of A.D. 1640 (Table 1), until the upper $\sim 100$ $\mathrm{m}$ of the ocean temperature reach an approximate steady state. We use the so-called acceleration technique (Bryan 1984) in the early part of this spinup phase to speed up the ocean model convergence to the steady-state solution. The model is then integrated without acceleration during the later part of the spinup phase to ensure the consistency of the solutions. The model is further integrated for another 76 years to be used in our analysis and to provide initial conditions for the TMM simulations.

In the TMM simulations, a time-varying forcing, which includes the effect of solar activity and volcanic eruptions, is applied. The forcing is crudely represented in the model in terms of changes in the total solar irradiance (TSI) without any change in the spectral distributions. The volcanic forcing data are based on Crowley (2000), and solar forcing data are constructed by linearly scaling Crowley (2000) to Lean et al. (1995) over the last 400 years. Note that there are large uncertainties in these reconstructions, which are discussed in section 5 in detail. The annual mean TSI values related to solar variations are linearly interpolated in time, while those related to volcanic eruptions are kept constant throughout the year, resulting in a squarelike forcing (Fig. 1). By doing so, we allow the annual radiative forcing due to volcanic eruptions to be consistent with that used by Crowley (2000) and also introduce no bias in forcing to a particular season. Note that a similar implementation was employed by Zorita et al. (2004). The solar forcing gradually decreases from 1640 to 1688 by $1.30 \mathrm{~W} \mathrm{~m}^{-2}$ in TSI, followed by a continuous increase until 1715 by $0.47 \mathrm{~W} \mathrm{~m}^{-2}$. There are five major volcanic forcing peaks: A.D. 1641, 1667, 1674, 1681, and 1695. These volcanic forcing peaks range from -22.0 to $-9.6 \mathrm{~W} \mathrm{~m}^{-2}$ in TSI. In the real world, peaks of volcanic forcing could occur in the following year of volcanic eruptions as it takes on the order of months for stratospheric sulfate aerosols to spread over from low to high latitudes. In this paper, however, we simply define peak volcanic forcing years as volcanic eruption years. We conduct an ensemble of six transient simulations, in which the integrations start from different years in the SMM simulation. Starting years are at least 10 years apart from each other to maintain the independence of each ensemble member. The greenhouse gas concentrations $\left(\mathrm{CO}_{2}, \mathrm{CH}_{4}, \mathrm{~N}_{2} \mathrm{O}, \mathrm{CFC}-11\right.$, and CFC-12) are fixed at the level in A.D. 1640 based on ice core records (Blunier et al. 1995; Flückiger et al. 2002; Siegenthaler et al. 2005) because radiative forcing changes due to these gases during the Maunder Minimum are estimated to be too small to significantly influence the climate. Additionally, a single STMM simulation is conducted in which volcanic forcing is removed from the TMM simulations.

Note that the effect of variations in orbital parameters is not considered in the present study, that is, A.D. 1990 orbital parameters are used in all experiments. Forcings associated with land-use change and tropospheric aerosols are also not included.

\section{Results \\ a. Temperature changes}

To facilitate the interpretation of the results and characterize the model against other coupled GCMs, we estimate the approximate climate sensitivity of the 


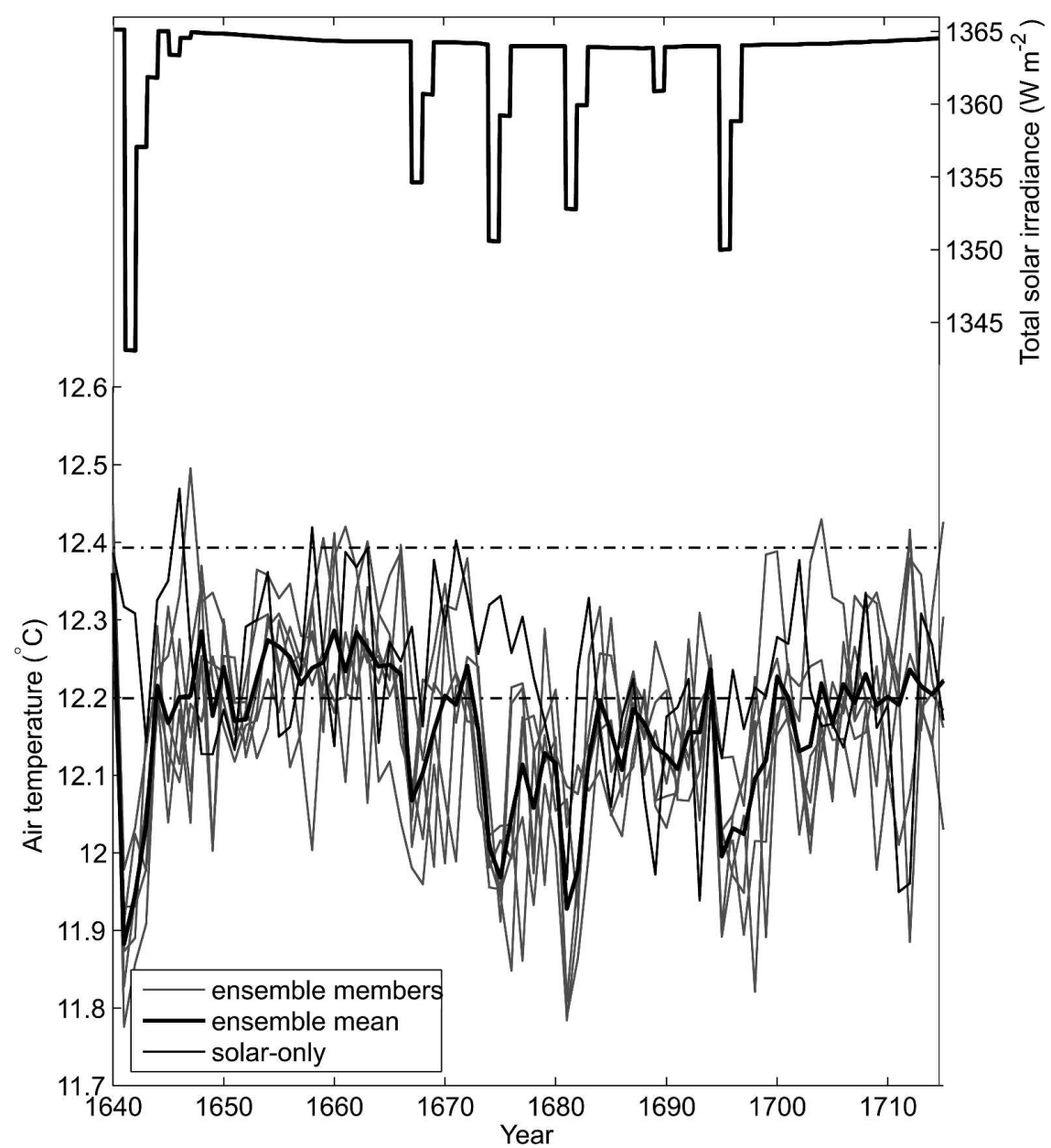

FIG. 1. (top) Total solar irradiance used in the TMM simulations. Abrupt drops correspond to volcanic forcing, while gradual changes represent solar forcing. (bottom) Simulated annual global-mean near-surface air temperature changes. Gray lines represent each ensemble member in the TMM simulations, thick solid line represents the TMM ensemble mean, and thin solid line represents the STMM simulation. The horizontal dashed-dotted lines indicate \pm 1 standard deviation of the SMM simulation centered on its mean.

model from the CTRL and SMM simulations. The annual global-mean near-surface air temperature in the CTRL and SMM simulations are $13.8^{\circ}$ and $12.3^{\circ} \mathrm{C}$, respectively. After taking into account the radiative imbalance at the top of the atmosphere, it yields the climate sensitivity parameter of about $0.68 \mathrm{~K}\left(\mathrm{~W} \mathrm{~m}^{-2}\right)^{-1}$ (Table 1). This is equivalent to $2.5^{\circ} \mathrm{C}$ global warming between equilibrium states under the doubling of atmospheric $\mathrm{CO}_{2}$ concentration $\left(3.7 \mathrm{~W} \mathrm{~m}^{-2}\right.$ : Ramaswamy et al. 2001). This value is slightly larger than the one in the higher-resolution setting of the same model (Kiehl and Gent 2004), and it belongs to the lower climate sensitivity group in the models used for the projections of future climate change in the Intergovernmental Panel on Climate Change (IPCC) Third Assessment Report (TAR; Cubasch et al. 2001). Therefore, we as- sume that the results in this study are conservative and a higher sensitivity would show even larger responses.

The annual global-mean near-surface air temperature changes are shown in Fig. 1. Temperature changes in the SMM and TMM simulations are distinctive, and the effect of external forcing on global-mean temperature is obvious. The departures in the TMM simulations from the SMM simulation is prominent during the years of major volcanic eruptions. In addition to these abrupt excursions, low-frequency variability is noticeable. There is a cooling trend approximately from 1660 to 1680 and a warming trend from 1680 to 1715 . The identification of the causes of the low-frequency variability between solar and volcanic forcing is not self-evident. Although the shape of the long-term trend in temperature changes is somewhat similar to that in the solar 
forcing, the repeating volcanic eruptions and the inertia of the climate system might be able to create a similar shape. Nevertheless, we attribute the long-term trends mainly to the solar forcing owing to the following reasons: the peak-to-peak solar forcing between 1640 and 1688 is about $0.23 \mathrm{~W} \mathrm{~m}^{-2}$ in radiative forcing and may account for as much as $0.16^{\circ} \mathrm{C}$ temperature change if the system is allowed to adjust to a modified forcing for an extended period of time. In addition, the response time of the global-mean near-surface air temperature to volcanic forcing is about $4 \mathrm{yr}$ in this model (discussed in more detail in section 4d; see also Fig. 17), and therefore the signals from each volcanic forcing should be well separated. Although it is only one realization, the STMM simulation supports this interpretation.

The standard deviation of the annual global-mean near-surface air temperature in SMM and TMM simulations are $0.10^{\circ}$ and $0.12^{\circ} \mathrm{C}$, respectively. The latter value is the average of six standard deviations calculated from each TMM simulation. In detection and attribution studies of climate change, uncertainty ranges are often estimated using the model-generated internal variability, and hence the results rely on the assumption that models produce the correct magnitude of internal variability (Mitchell et al. 2001). There is no direct way to verify the model-generated internal variability because the instrumental records are already subject to increasing atmospheric greenhouse gases and other anthropogenic, radiatively active species. To some extent, the confidence may be given if the model is capable of stimulating the natural variability seen in proxy reconstructions. Some reconstructions of temperature exhibit larger variability than that generated internally by models (Mitchell et al. 2001). The result shown here suggests that the difference could be explained by the natural, external forcing. Since we have only one realization of the SMM simulation, we also compare the mean standard deviation of six TMM simulations with standard deviations of a large number of 76-yr data segments from the long CTRL simulation, in order to gain a more robust picture (Fig. 2). The ratio in standard deviation of the TMM simulations to the CTRL simulation varies over a wide range of values. Nevertheless, it generally shows the increase of variability, consistent with the above result.

A comparison of low-pass filtered Northern Hemisphere near-surface air temperature changes between model simulations and proxy-based reconstructions is given in Fig. 3. The low-pass filter is imposed to minimize the effect of the internal, interannual variability and sampling fluctuations on the comparison. The comparison is made in terms of departures from the average

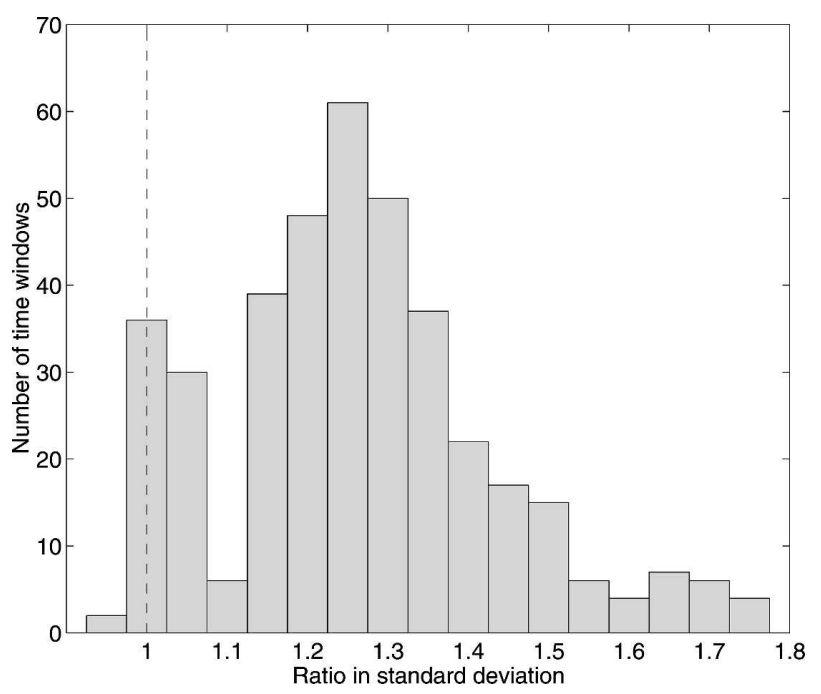

FIG. 2. Histogram for ratios in standard deviation of the TMM simulations to the CTRL simulation. Each ratio is calculated between the average standard deviations of six TMM simulations and the standard deviation of each segment of the time series extracted from the CTRL simulation by applying a 76-yr-long sliding window. A total of 390 time windows are sampled. The bin width is 0.05 . The level where the two standard deviations are equal is indicated by the vertical dashed line.

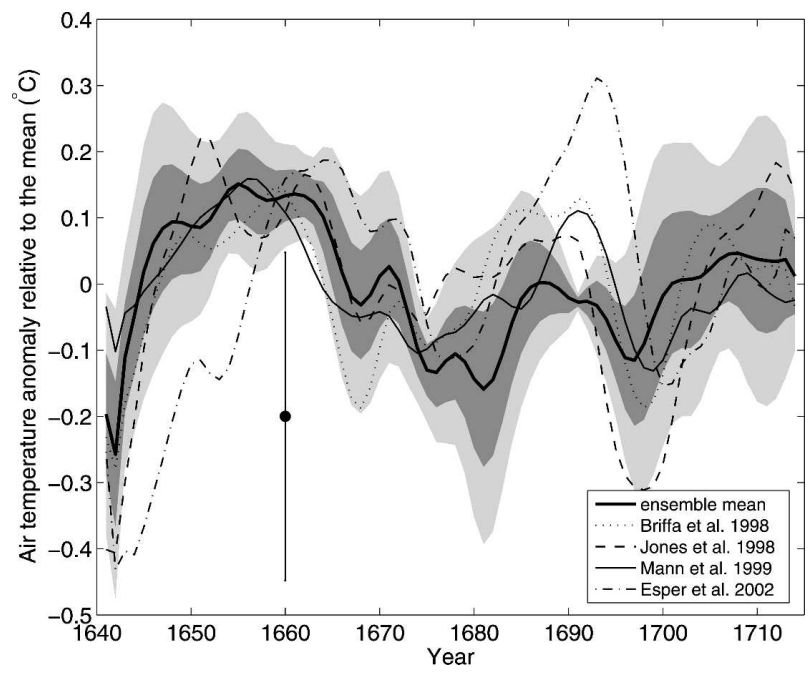

FIG. 3. Comparison of Northern Hemisphere near-surface air temperature changes between the ensemble mean of the TMM simulations and proxy-based reconstructions of Briffa et al. (1998), Jones et al. (1998), Mann et al. (1999), and Esper et al. (2002). For clarity and the emphasis on decadal variations, a lowpass filter is imposed on each time series, which removes fluctuations with periods less than $4 \mathrm{yr}$ (Hurrell 1995). Temperature anomalies are expressed as departures from the mean of each time series. The dark and light shadings, respectively, represent \pm 1 and \pm 2 standard deviations of ensemble members centered on the ensemble mean. The size of $\pm 2 \sigma$ errors averaged over the Maunder Minimum period in Mann et al. (1999) is also indicated by a vertical line. 
temperatures over the Maunder Minimum. The simulated Northern Hemisphere temperature changes agree relatively well with the reconstructions by Briffa et al. (1998), Jones et al. (1998), and Mann et al. (1999) except near 1690 when the model ensemble members exhibit unusually small spread by chance and all reconstructions exceed two standard deviations from the ensemble mean. There is little agreement between the model simulation and Esper et al. (2002). Mann et al. (1999) shows a smaller cooling in the early 1640s compared to other data whereas Jones et al. (1998) exhibits larger cooling in the late 1690s compared to other data. The correlation coefficients between the ensemble mean and reconstructions by Briffa et al. (1998), Jones et al. (1998), Mann et al. (1999), and Esper et al. (2002) are $0.60,0.68,0.68$, and 0.17 , respectively. Esper et al. (2002) has been criticized in that they use only tree ring records, which tend to bias the reconstruction toward warm growing seasons, rather than annual mean, and also that they used records from only 14 extratropical sites (Mann et al. 2002). We test this possibility by using only simulated data from those 14 grid points that correspond to tree ring sites in Esper et al. (2002) and during the warm season (April to September). The correlation coefficients between the "new" and "original" Northern Hemisphere temperature records calculated from the six TMM simulations range from 0.58 to 0.69 with a mean of 0.63 ( 0.75 to 0.85 with a mean of 0.82 if low-pass filtered). Also, the new record does not improve agreement with model simulations. We cannot, however, completely eliminate the possibility that the reconstruction by Esper et al. (2002) represents a more realistic temperature history than other reconstructions. The simulated results do not contain information related to the long-term memory in the climate system prior to 1640 and hence may underestimate the centennial-scale variability. Indeed, the most recent reconstruction by Moberg et al. (2005), whose correlation coefficient with the TMM ensemble mean is 0.50 , shows much larger centennial variability than previously considered.

The agreement of TMM simulations with some reconstructions does not guarantee that the climate sensitivity of the model, defined as the equilibrium temperature response to the external forcing, is correct even if the forcing were accurate. Poor correlations between the STMM simulation and the reconstructions suggest that the agreement arises mainly from volcanic events, and the volcanic forcing is too short for the climate system to fully adjust. On the other hand, it gives some confidence that the model is capable of simulating a realistic decadal variability in response to the natural external forcing, at least on hemispheric scales.

Since all ensemble members show the consistent global and hemispheric mean temperature changes (Figs. 1 and 3), the relatively high correlations between simulations and proxy reconstructions do not likely occur by chance. To ensure this, we also calculate the correlation coefficients in the Northern Hemisphere temperature between reconstructions and a large number of 76-yr data segments from the long CTRL simulation (Fig. 4). The correlation coefficients between each TMM ensemble member and Jones et al. (1998), or each TMM ensemble member and Mann et al. (1999), range from 0.40 to 0.81 or 0.41 to 0.71 , respectively. Correlation coefficients between the two reconstructions and some segments of the CTRL simulation exceeds the lowest thresholds of these ranges. However, the average of six correlation coefficients calculated from each TMM ensemble member and Jones et al. (1998) or each TMM ensemble member and Mann et al. (1999) are both 0.58 , and there is no combination of six segments of the CTRL simulation that reaches this value. In addition, correlation coefficients between the ensemble mean and the two reconstructions are much higher than this value. Therefore, we conclude that the high correlations between simulations and proxy reconstructions do not occur by chance. This additional evidence supports our interpretation that the model does reproduce a realistic hemispheric-scale temperature variability on decadal time scales. Note that these results are insensitive to the use of the low-pass filter and the window length.

Figures $5 \mathrm{a}$ and $5 \mathrm{~b}$ show the temporal evolution of the annual zonal-mean near-surface air temperature anomaly in the model ensemble mean and the reconstruction by Mann et al. (1999), respectively. As stated already, a large cooling in the early 1640s in the model ensemble mean is missing in the reconstruction, and a warming near 1690 in the reconstruction is missing in the model ensemble mean. Another noticeable difference is that the model ensemble mean shows large variabilities in the Northern Hemisphere mid- to high latitudes, while the reconstruction only shows moderate variabilities. Nevertheless, the overall agreement between the two is encouraging. Note that the comparison in the north of $60^{\circ} \mathrm{N}$ is not shown as there are few data points that are unlikely to represent a zonal mean. Each model ensemble member shows different temporal evolution in those latitudes, indicating a dominance of internal variability and reflecting noise rather than signal. To the south of $60^{\circ} \mathrm{N}$, however, all ensemble members exhibit a structure similar to the ensemble mean (not shown), and hence the result is robust. In general, 
a)

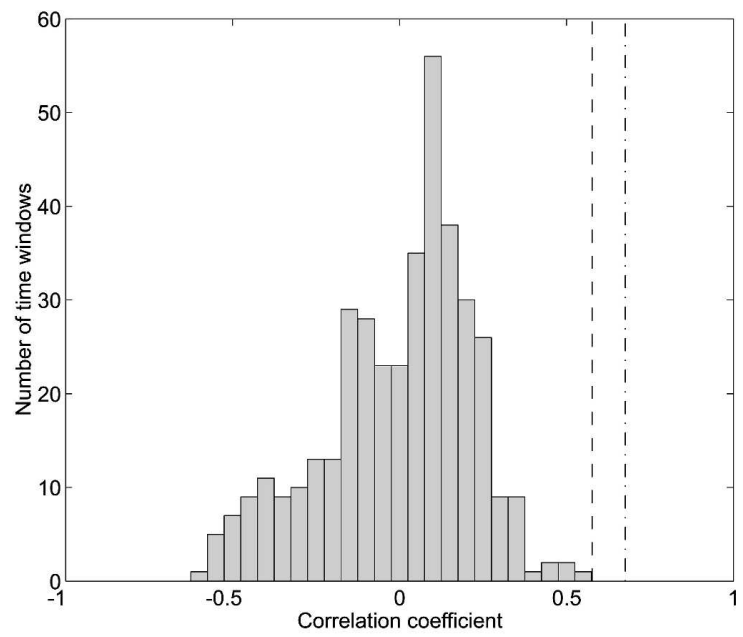

b)

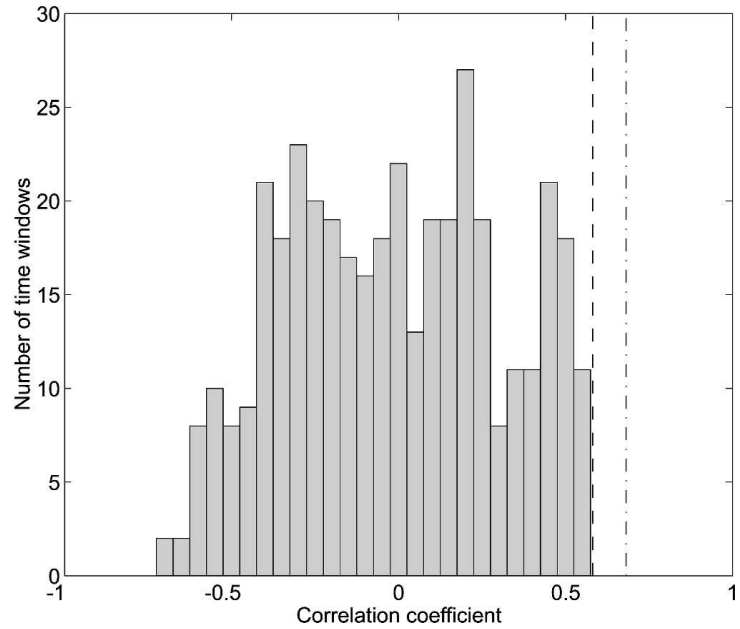

FIG. 4. Histogram for correlation coefficients between proxybased reconstructions and 390 time windows along the CTRL simulation in Northern Hemisphere near-surface air temperature. Each correlation coefficient is calculated between each segment of the time series extracted from the CTRL simulation by applying a 76-yr-long sliding window and reconstructions from A.D. 1640 to 1715: (a) Jones et al. (1998) and (b) Mann et al. (1999). The bin width is 0.05 . Vertical dashed lines indicate the mean of the correlation coefficients between each ensemble member in the TMM simulations and reconstructions. Vertical dashed-dotted lines indicate the correlation coefficient between the ensemble mean and reconstructions. None of the CTRL windows reaches the high correlations between the forced ensemble and the proxy reconstruction.

proxy-based reconstructions necessarily but heavily rely on tree ring records, which have a bias to represent warm, growing seasons. We tested this possibility by using only warm season data from model output, but better agreement is not obtained.

An important question in investigating the externally forced variability is whether the response is distinguish- a)

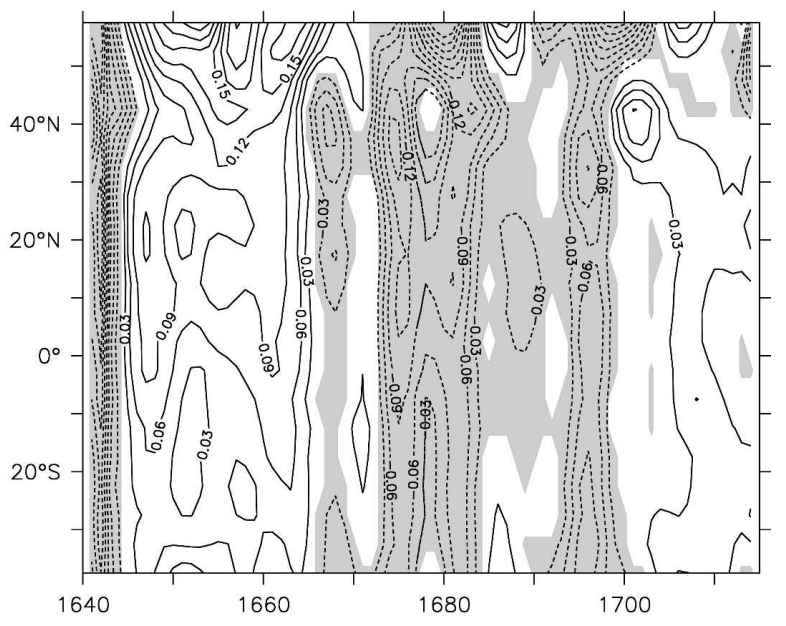

b)

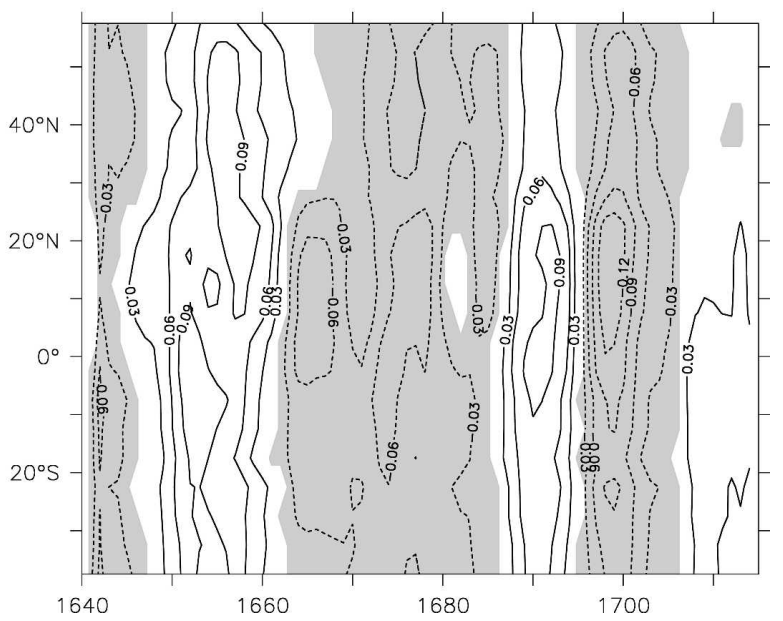

FIG. 5. Hovmöller diagram for zonal-mean near-surface air temperature changes during the Maunder Minimum $\left({ }^{\circ} \mathrm{C}\right)$ : (a) ensemble mean of the TMM simulations and (b) Mann et al. (1999) reconstruction. All values are subject to the same low-pass filter used in Fig. 3. The zonal-mean field of the model output is obtained by first interpolating the data to reconstruction grids, and then using the values only at grid points where reconstruction data exist. Contour interval is $0.03^{\circ} \mathrm{C}$ and zero contours are omitted. Negative values are indicated by shading.

able from the internal variability. This notion is particularly important when one goes toward regional scales and attempts to compare directly with proxy records. As TSI forcing in the TMM simulations is always smaller than the SMM simulation and the Maunder Minimum is known to be one of the distinct cold periods during the last centuries, we choose the mean temperature over the 76-yr Maunder Minimum as a target variable and examine if the difference in the mean temperature between SMM and TMM simulations is distinguishable. 
First, we investigate large-scale signal-to-noise relations (Fig. 6). Here signal and noise denote the externally forced response and internal variability, respectively. The mean temperature of the SMM simulation is estimated with a $5 \%-95 \%$ confidence interval. The mean temperature of each TMM ensemble member is then calculated and evaluated in terms of a departure from the mean of the SMM simulation. This procedure is repeated for all regions individually. Although the question of the suitability of the ensemble size remains, all ensemble members in the TMM simulations are well separated from the SMM simulation. The Northern Hemisphere and land averages show larger internal variability in the SMM simulation and a wider spread of ensemble members than others, presumably because of the smaller heat capacity of the continents.

Second, we investigate regional-scale signal-to-noise relations (Figs. 7 and 8). Although the use of predetermined regional masks is somewhat subjective, the interpretation of the results is rather straightforward, and it provides useful information in terms of the possibility of comparison with proxy records. Figure 8 exhibits cooling in the TMM ensemble members in most regions. However, in Alaska, Greenland, and northern Europe, the TMM ensemble members are not clearly

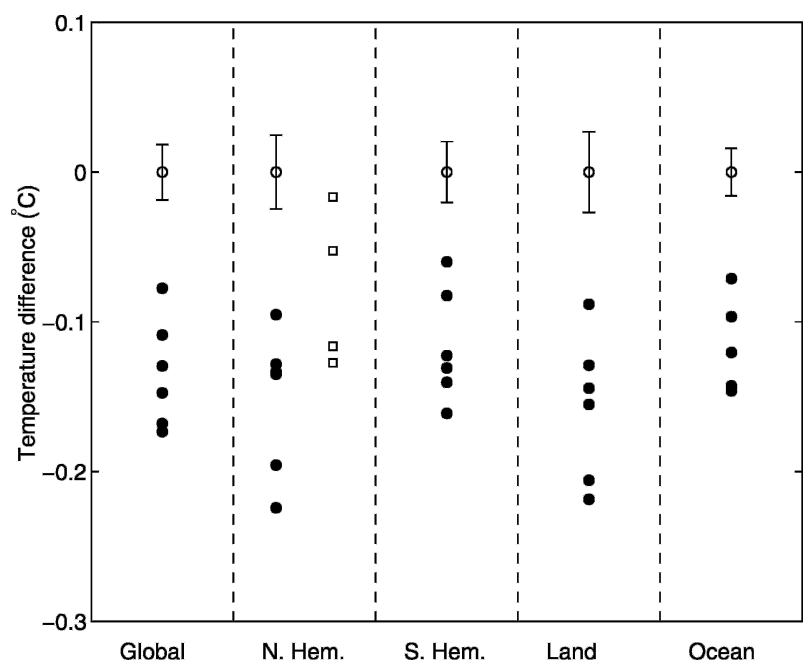

FIG. 6. Comparison in mean Maunder Minimum near-surface air temperature between the SMM and TMM simulations. The mean temperatures in the SMM simulation are indicated by empty circles, but shifted to zero. The 5\%-95\% confidence intervals for the estimates of the mean assuming the $t$ distribution are represented by vertical bars. The mean temperatures in each ensemble member of the TMM simulations are indicated by solid circles. Deviations of mean Maunder Minimum temperatures (1640-1715) from the long-term preindustrial means (1716-1850), calculated from reconstructions, are also shown. These are indicated by squares, in the order of Briffa et al. (1998), Mann et al. (1999), Esper et al. (2002), and Jones et al. (1998) from the top.

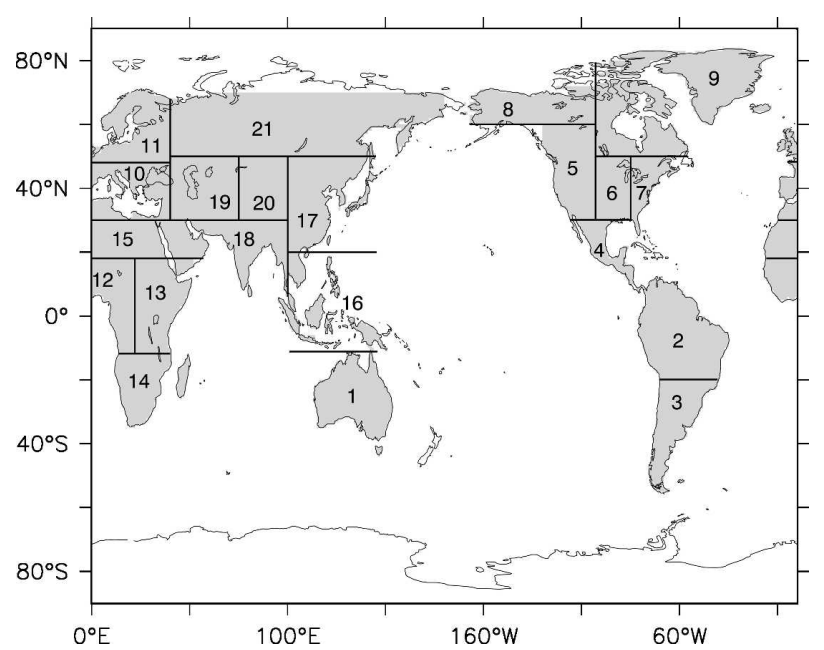

FIG. 7. Region masks used to analyze data over land. The definition of regions in terms of latitude and longitude follows Giorgi and Francisco (2000).

distinguishable from the SMM simulation. This implies that the comparison with proxy records in these regions is challenging. Some other regions such as southern South America, western North America, and central North America show that one of the ensemble members overlaps with the uncertainty range of the SMM simulation, implying that proxy records may not capture the externally forced signal beyond internal variability in these regions. In winter, the signal-to-noise relation deteriorates in most regions whereas it improves in some regions and deteriorates in others in summer (not shown). In addition to the difference in the mean, we also investigates the signal-to-noise relation on multidecadal time scales, that is, a spatial pattern that corresponds to a positive trend from 1680 to 1715 in annual global-mean near-surface air temperature (Fig. 1). A linear trend in each TMM ensemble member is calculated, and the range of trends in all ensemble members is analyzed and compared with trends calculated from the Mann et al. (1999) reconstruction (Fig. 8). The ensemble mean shows positive trends in most of the regions. Owing to the internal variability inferred from the spread of ensemble members, even the signs of the trends cannot be definitely determined. This implies that caution has to be exercised if the model simulations are compared directly with proxy records because proxy records represent only one unique realization. In contrast to the model simulations, the reconstruction exhibits virtually no trend in most regions. It seems that the model overestimates the trend in many regions although reconstructions still reside within the range of ensemble members in about half of the regions. 


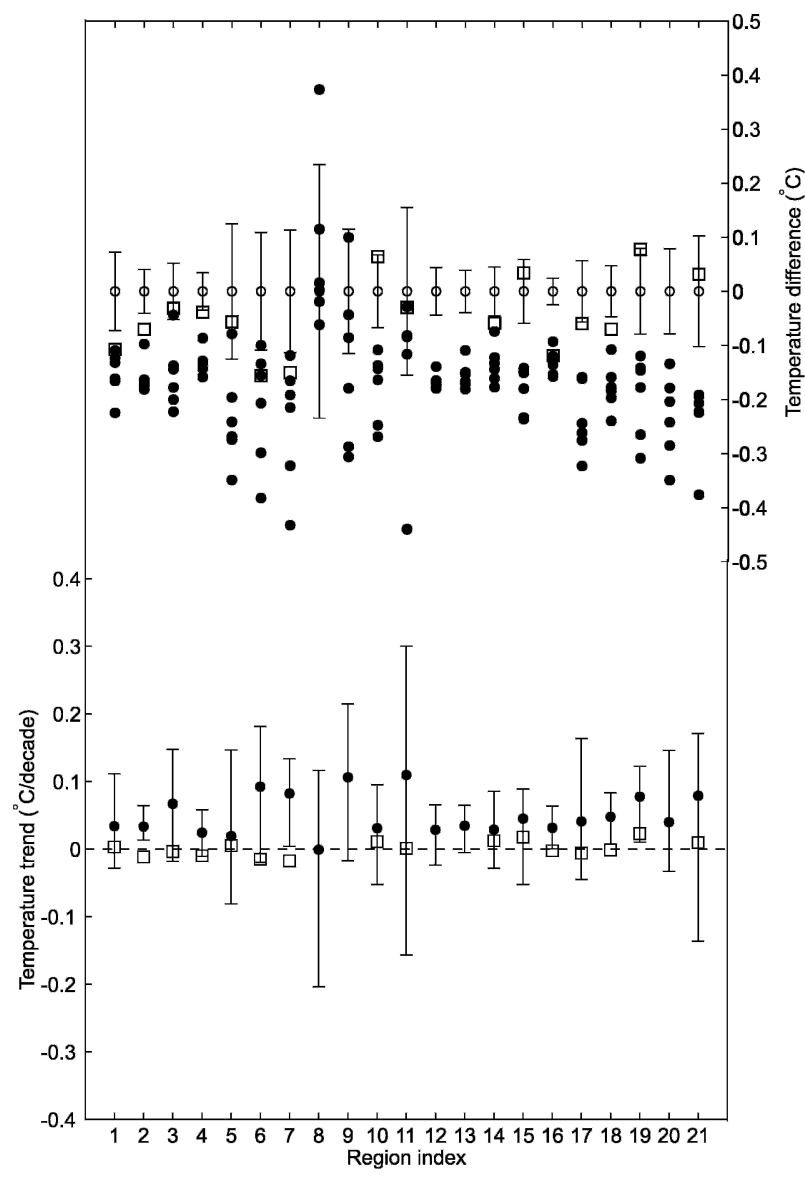

FIG. 8. Near-surface air temperature changes in regions defined in Fig. 7. Model output is first interpolated onto $1^{\circ}$ by $1^{\circ}$ latitudelongitude grids, and then averaged over each region. Values from Mann et al. (1999) are indicated by squares and are calculated only in those regions where the existing data cover more than $50 \%$ of the area of each region. (top) As in Fig. 6; (bottom) linear trends from 1680 to 1715 . The range of trends for six ensemble members of the TMM simulations are represented by vertical bars with its mean indicated by solid circles.

\section{b. Precipitation changes}

The annual global-mean precipitation in the presentday and SMM simulations are 2.79 and $2.71 \mathrm{~mm} \mathrm{day}^{-1}$, respectively. Assuming a linearity of hydrological response to radiative forcing, it corresponds to roughly $1.3 \%\left(\mathrm{~W} \mathrm{~m}^{-2}\right)^{-1}$, or equivalently the hydrological sensitivity of $4.8 \%$ under the doubling of atmospheric $\mathrm{CO}_{2}$ concentration. This value belongs to the lower hydrological sensitivity group in the models considered in Cubasch et al. (2001), consistent with the low climate sensitivity.

The annual global-mean precipitation changes are shown in Fig. 9. The structure of the temporal evolution in precipitation is similar to temperature changes (Fig. 1 ), that is, sudden drops due to volcanic eruptions, and

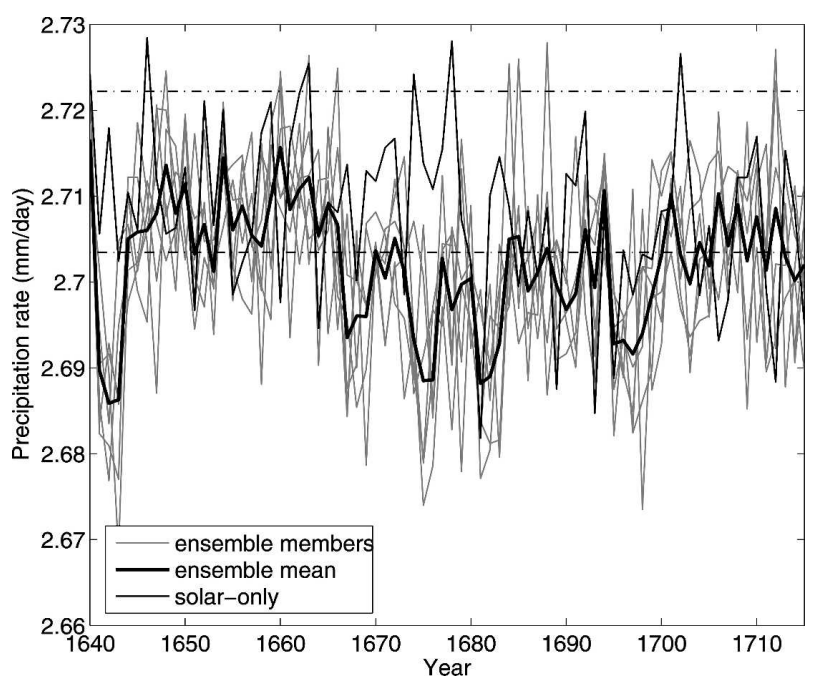

FIG. 9. As in Fig. 1 (bottom), but for precipitation rate.

a slow decreasing trend approximately from 1660 to 1680 , and an increasing trend thereafter. The difference between the SMM and TMM simulations is clear in most of the period.

The standard deviations of annual global-mean precipitation in the SMM and TMM simulations are $9.4 \times$ $10^{-3}$ and $10.5 \times 10^{-3} \mathrm{~mm} \mathrm{day}^{-1}$, respectively. The latter value is the average of six standard deviations calculated from each TMM simulation. As in the analysis for temperature in the previous section, we also compare the mean standard deviations of the six TMM simulations with standard deviations of a large number of 76-yr data segments from the long CTRL simulation, in order to gain a more robust picture (Fig. 10). It ex-

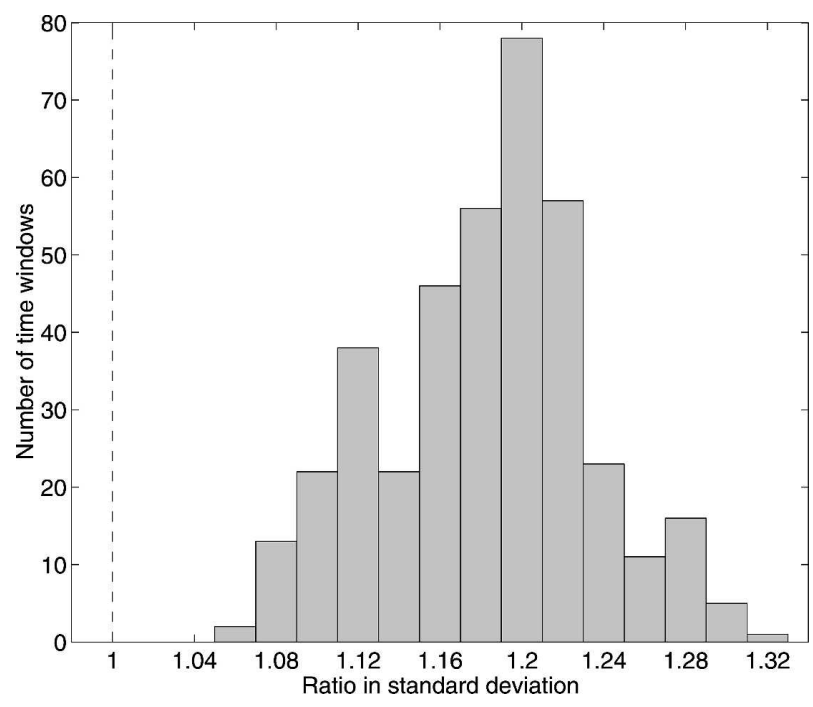

FIG. 10. As in Fig. 2, but for precipitation rate and the bin width of 0.02 . 
hibits a consistent $10 \%-30 \%$ increase in the standard deviation when the model is externally forced.

As in the analysis for temperature (Fig. 6), largescale signal-to-noise relations for precipitation are investigated (Fig. 11). In contrast to temperature, some of the TMM ensemble members overlap with the uncertainty range of the SMM simulation in hemispheric and land averages. This implies that precipitation has a smaller signal-to-noise ratio than temperature, making it more difficult to extract the externally forced signal. The regional-scale analysis shows further deterioration of the signal-to-noise relation (Fig. 12). The externally forced signal is distinguishable from the internal variability only in Greenland. If we assume that six ensemble members represent the full range of probability density functions (PDFs) under the solar and volcanic forcing of the TMM simulations, it can be said that the PDFs shift toward more precipitation in some regions (e.g., regions 4, 5, 6, 10, and 19) and less precipitation in others (e.g., regions 8 and 21) under the TMM forcing conditions. However, there is no guarantee that proxy records capture such signals. In winter, the externally forced signal is not clearly distinguishable from the internal variability in all regions (not shown). In summer, it is distinctive only in western North America where the externally forced signal indicates wetter conditions, consistent with Cook et al. (2004).

\section{c. Changes in the upper ocean}

The annual global-mean ocean temperature changes in the upper $\sim 100 \mathrm{~m}$ layer are shown in Fig. 13. They exhibit a similar structure in the temporal evolution to

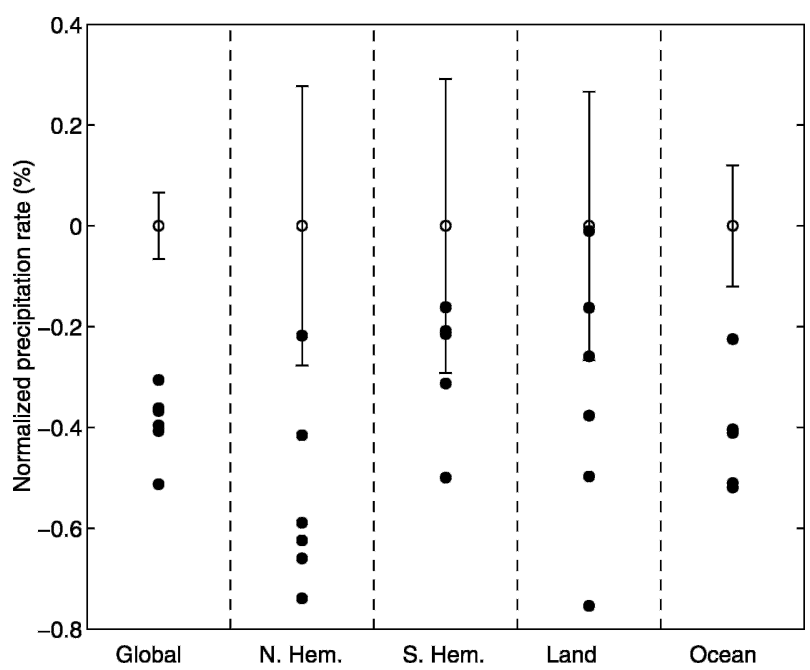

FIG. 11. As in Fig. 6, but for precipitation rate. The precipitation rate is normalized by the mean precipitation rate of each region in the SMM simulation.

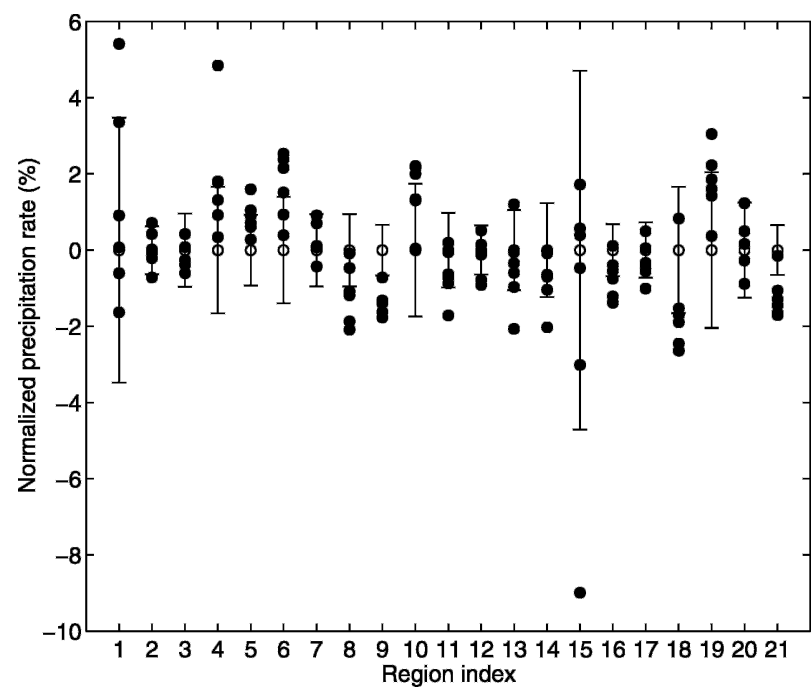

FIG. 12. As in Fig. 8, but for precipitation rate. The precipitation rate is normalized by the mean precipitation rate of each region in the SMM simulation.

the near-surface air temperatures and, visually, they are distinguishable from the SMM simulation. Salinity, on the other hand, does not show a significant difference from the SMM simulation (not shown) although the presence of a small drift in salinity field of the SMM simulation makes the interpretation slightly more complicated. Note that the analysis in each level of the ocean, rather than the average over $100 \mathrm{~m}$ in depth, does not make much difference in the results.

The basin-scale signal-to-noise relation is investigated for different ocean regions as given in Fig. 14. For ocean temperature, the signal is detected in all basins

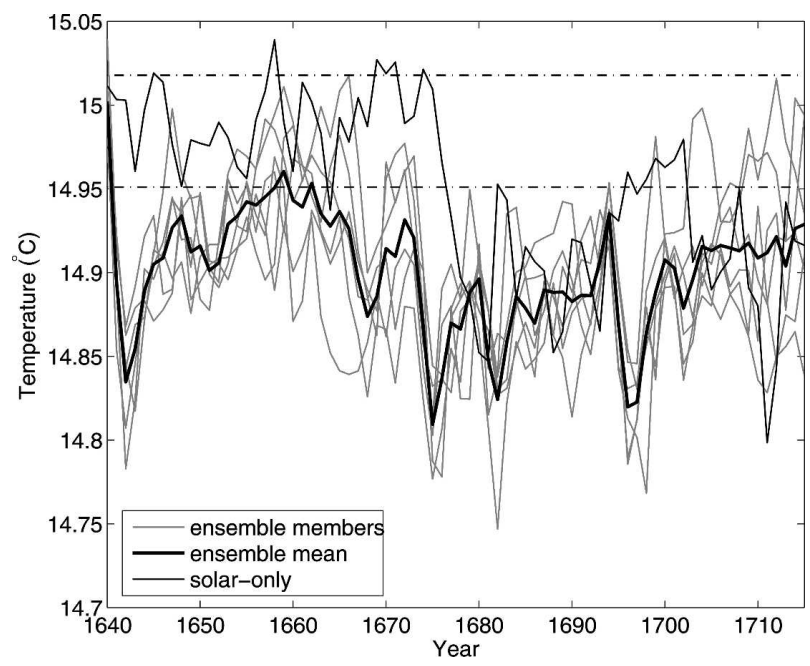

FIG. 13. As in Fig. 1 (bottom), but for global-mean ocean temperature in the upper 100-m layer. 


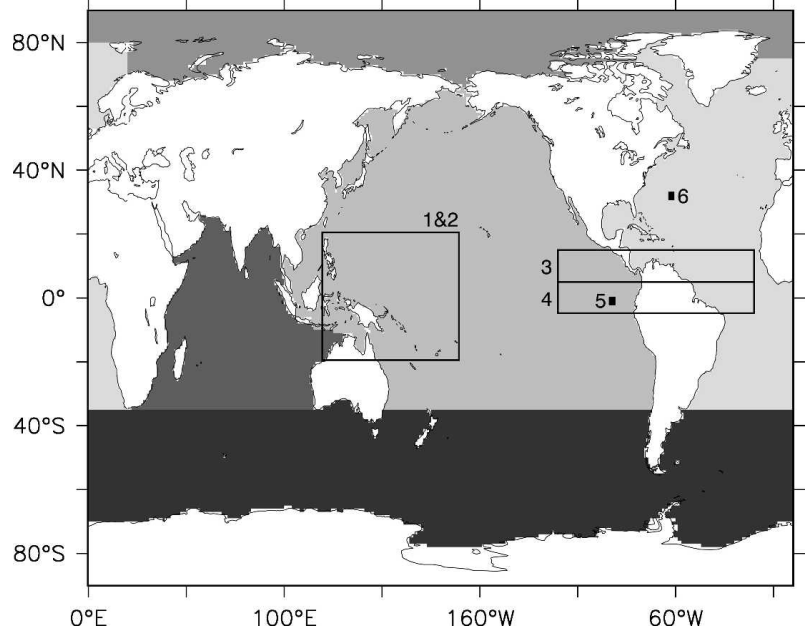

FIG. 14. Region masks used to analyze data in the ocean: Atlantic, Pacific, Arctic, Indian, and Southern Oceans. Also shown are regions of indices in Fig. 16.

except in the Arctic where the sea ice insulates the ocean from the atmosphere (Fig. 15a). The sign of large-scale cooling in sea surface temperature (SST) during periods of reduced solar activity is indicated from several proxy records in the western tropical $\mathrm{Pa}$ cific based on coral $\mathrm{Sr} / \mathrm{Ca}$ and $\mathrm{U} / \mathrm{Ca}$ records (Hendy et al. 2002), in the eastern tropical Pacific based on coral $\delta^{18} \mathrm{O}$ records (Dunbar et al. 1994), and in the Sargasso Seas based on $\delta^{18} \mathrm{O}$ in marine sediments (Keigwin 1996). SSTs in the corresponding three locations in the TMM simulation also exhibit coolings compared to the SMM simulation (indices 1, 5, and 6 in Fig. 16). On the contrary, planktonic foraminifera abundance in marine sediments from the Laurentian Fan (off Newfoundland) indicates warm conditions (Keigwin and Pickart 1999), while the model does not show such a warming (not shown). This may be due to poor representation of the Gulf Stream, which influences the SST variations of this region, in the coarse-resolution ocean model. In addition, the marine sediment records from the Sargasso Sea and Laurentian Fan, respectively, represent cooling and warming over the entire Little Ice Age and are not necessarily captured by the forced experiments during the Maunder Minimum alone. Clearly, reconstructions of spatial patterns of the SST anomaly during the Maunder Minimum would be useful for the modeldata comparison.

In contrast to temperature, salinity does not show a clear difference between TMM and SMM simulations on the global average, which could be influenced by atmospheric moisture content and sea ice volume (Fig. $15 \mathrm{~b})$. Note that both atmospheric moisture content and sea ice volume are linked to "detected" global-mean a)

b)
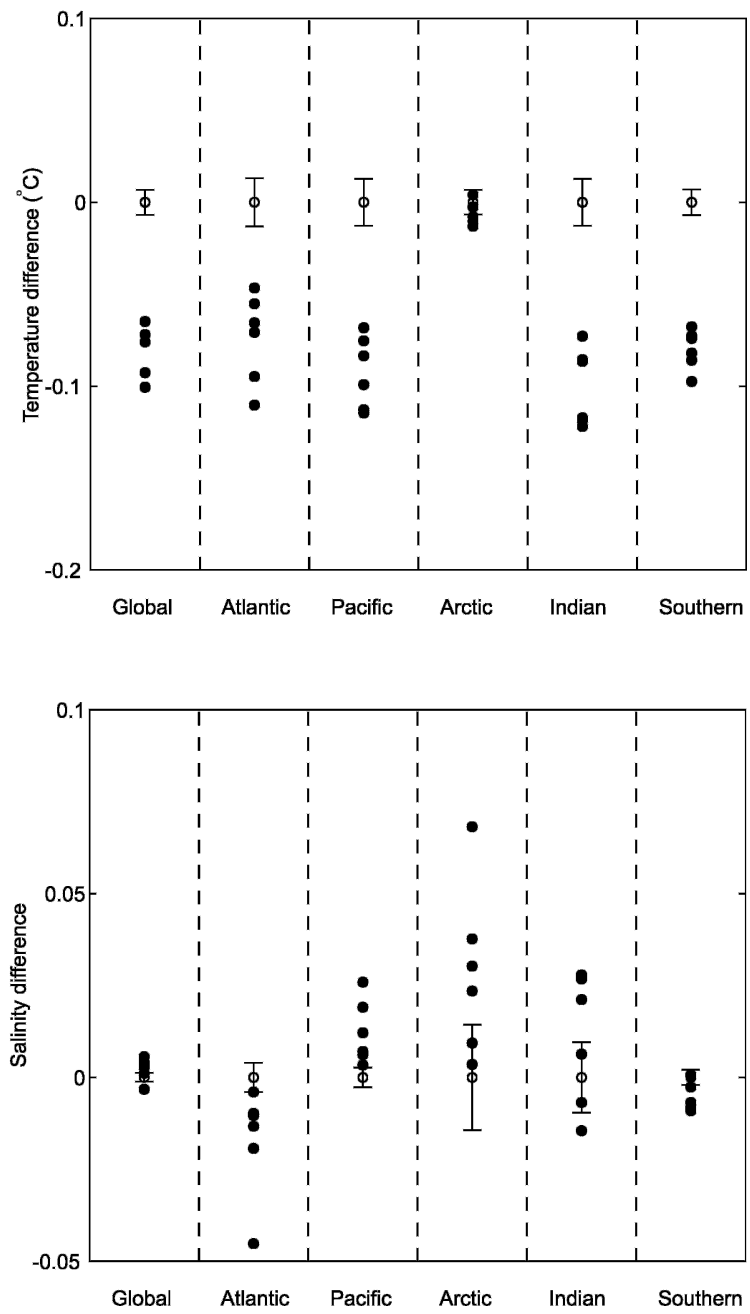

FIG. 15. As in Fig. 6, but for the upper 100-m layer of the ocean: (a) mean temperature and (b) mean salinity.

temperature. Interestingly, however, in the Atlantic and Pacific, the salinity signal is detectable with opposite signs, that is, decreased salinity in the Atlantic and increased salinity in the Pacific. This is consistent with coral $\delta^{18} \mathrm{O}$ records from the Great Barrier Reef that show higher salinity in the western tropical Pacific during the Little Ice Age (Hendy et al. 2002). Sea surface salinity (SSS) in the corresponding region from the TMM simulations also exhibits higher values compared to the SMM simulation (index 2 in Fig. 16). This is caused by the reduced net moisture transport from the Atlantic to the Indo-Pacific basins in low latitudes. The tropical cooling due to reduced solar activity and volcanic eruptions does not only decrease specific humidity, but also weakens the tropical convective activity resulting in the weakening of the Hadley circulation and the easterlies in the midtroposphere (indices 3 and 


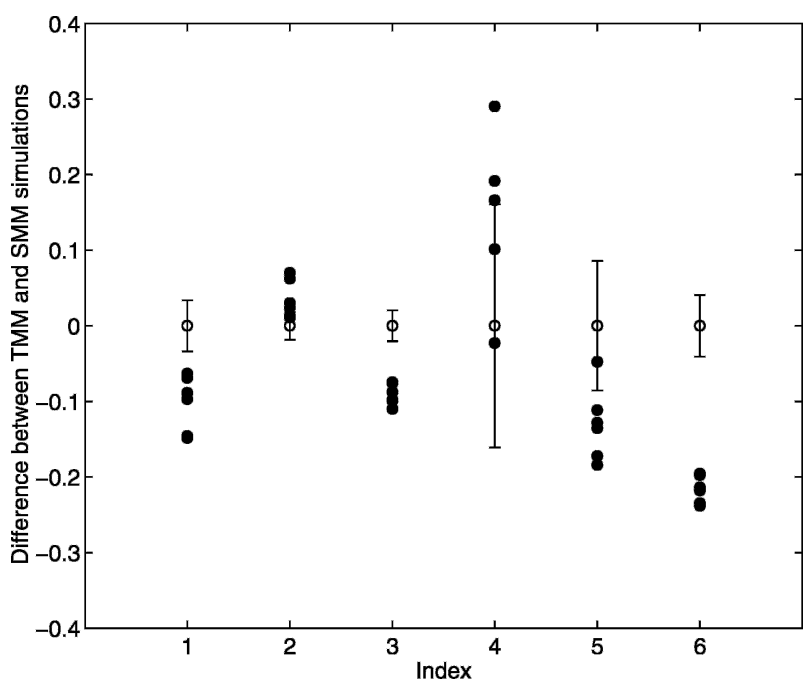

FIG. 16. Comparison between the SMM and TMM simulations in various variables averaged over the entire Maunder Minimum. The mean value in the SMM simulation is indicated by empty circles, but shifted to zero. The $5 \%-95 \%$ confidence intervals for the estimates of the mean are represented by vertical bars. The mean values in each ensemble member of the TMM simulations are indicated by solid circles. The indices on the horizontal axis define the following variables. Index 1: SST $\left({ }^{\circ} \mathrm{C}\right)$ from $20^{\circ} \mathrm{S}-20^{\circ} \mathrm{N}$, $120^{\circ} \mathrm{E}-170^{\circ} \mathrm{W}$; index 2 : SSS from $20^{\circ} \mathrm{S}-20^{\circ} \mathrm{N}, 120^{\circ} \mathrm{E}-170^{\circ} \mathrm{W}$; index 3: specific humidity $\left(\mathrm{g} \mathrm{kg}^{-1}\right)$ at $850 \mathrm{hPa}$ from $5^{\circ}-15^{\circ} \mathrm{N}, 120^{\circ}-20^{\circ} \mathrm{W}$; index 4: zonal wind $\left(\mathrm{m} \mathrm{s}^{-1}\right)$ at $500 \mathrm{hPa}$ from $5^{\circ} \mathrm{S}-5^{\circ} \mathrm{N}, 120^{\circ}-20^{\circ} \mathrm{W}$ (positive eastward); index 5: SST $\left({ }^{\circ} \mathrm{C}\right.$ ) from $1^{\circ} \mathrm{S}, 92^{\circ} \mathrm{W}$; and index 6: SST $\left({ }^{\circ} \mathrm{C}\right)$ from $32^{\circ} \mathrm{N}, 62^{\circ} \mathrm{W}$. Note that $5^{\circ}-15^{\circ} \mathrm{N}$ is chosen for specific humidity as the annual mean trade wind is strongest near the Atlantic-Pacific border, and $5^{\circ} \mathrm{S}-5^{\circ} \mathrm{N}$ is chosen for zonal wind as the annual mean specific humidity is highest in the model. Indices 1 and 2 correspond to the region where proxies from the Great Barrier Reef are available, index 5 corresponds to Galápagos, and index 6 corresponds to Sargasso Sea.

4 in Fig. 16). The net loss of salinity in the Atlantic in cold climate is consistent with the study by Zaucker and Broecker (1992) in which an atmospheric GCM experiment with doubling of $\mathrm{CO}_{2}$ exhibits the net gain of salinity in the Atlantic due to increased net moisture transport from the Atlantic to the Indo-Pacific basins. The ensemble members also tend to show larger salinity in the Arctic where temperature shows little difference (Fig. 15). Salinity increase in the Arctic is caused by the enhanced flow through Bering Strait rather than changes in surface freshwater fluxes. The throughflow increases by about $5 \%$ in the TMM ensemble mean relative to the SMM simulation. Surface freshwater fluxes also increases in the Arctic, which reduces salinity there. Note that the effect of increased salinity in the Pacific on the salt transport from the Pacific to the Arctic is negligible compared to the change in the throughflow strength. These results suggest that non- thermal proxy records could be useful to constrain the past history of the multidecadal variability.

\section{d. Response to volcanic forcing}

"Direct" response to volcanic forcing is analyzed using a composite (or superposed epoch) analysis: 30 composite members are constructed, for -1 to $+6 \mathrm{yr}$ relative to the volcanic eruptions, from the six TMM ensemble members in which each ensemble member contains five major eruptions; then the differences in the mean of the composite members between $-1 \mathrm{yr}$ (prevolcanic) and 0 to +6 (mid- and postvolcanic) years are tested using the nonparametric Mann-Whitney test. We include only one prevolcanic year, for each volcanic eruption, which represents "normal" or volcanic forcing free states in order to avoid overlap with responses to previous eruptions. Note that the Student's $t$ test gives essentially the same results in the following. Note also that the inclusion of corresponding years from the STMM simulation in normal years does not change the results either.

The annual global-mean near-surface air temperature response to volcanic forcing is shown in Fig. 17. The temporal evolution exhibits overall a similar structure as observations and other model simulations for recent volcanic eruptions (e.g., Robock and Liu 1994; Robock and Mao 1995; Soden et al. 2002; Broccoli et al. 2003). Near-surface air temperature is statistically distinguishable from internal variability up to 3 years after

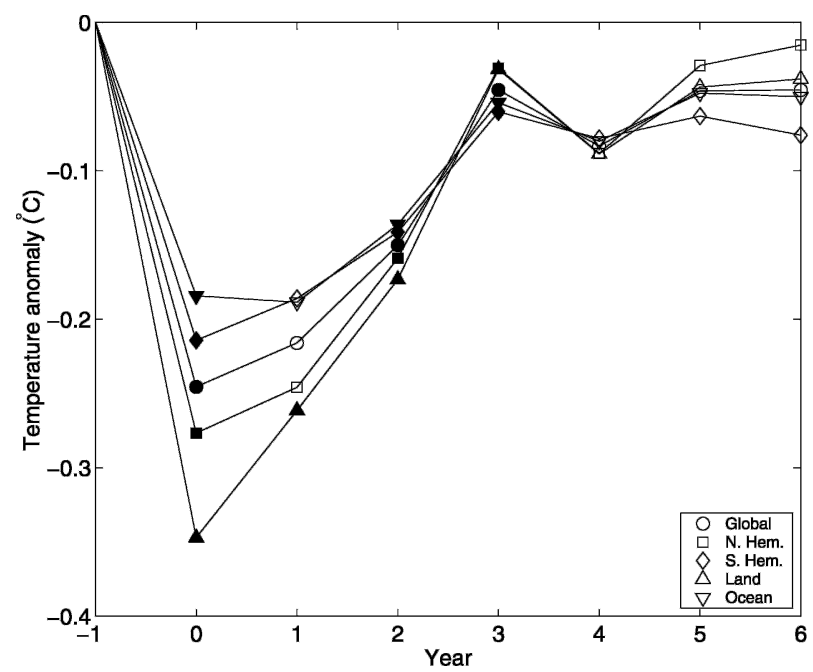

FIG. 17. Composite mean response of near-surface air temperature to 30 volcanic eruptions in the TMM simulations. Year of peak volcanic forcing is defined as year zero. Solid and empty symbols, respectively, represent statistically significant and nonsignificant values at the $10 \%$ level (of incorrectly rejecting the null hypothesis) using the Mann-Whitney test. See text for details. 
the volcanic eruptions, in agreement with Robock and Mao (1995) who used observational data. The strength of the response seems to be associated with the heat capacity of the system; that is, response over land is larger than that over ocean, and the Northern Hemisphere shows a larger response than the Southern Hemisphere. Observational and previous model studies also show that the magnitude of the response is larger in the Northern Hemisphere mean than the Southern Hemisphere mean (Robock and Liu 1994; Robock and Mao 1995). There is a lack in statistical significance in the following year of eruptions except for the land average, indicating a large spread of responses among composite members. Although statistically insignificant, we consider the response in this year as physically important since the response curve is consistent with the previous and following years. Furthermore, we speculate that it may suggest that volcanic forcing affects not only the mean climate but also the variance of the climate by changing its probability distribution. The precipitation exhibits a rather unstructured temporal response to volcanic forcing except for the global and land averages in which similar shapes of the response curve to those of temperature are seen (not shown). We interpret this unstructured temporal response in precipitation without a strong statistical significance as a highly "contaminated" volcanic signal by internal variability. The smaller signal-to-noise ratio in precipitation than temperature is also simulated by Robock and Liu (1994). In their study, however, Northern Hemisphere mean precipitation shows a "structured" volcanic response, while it is buried in noise in our simulations. In the global and land averages, there are reductions of precipitation in years of volcanic eruptions and gradual recoveries to normal values thereafter, and the signal is statistically distinguishable up to 3 years after the eruptions.

As demonstrated earlier, on regional scales, the detection of mean changes and multidecadal trends in both temperature and precipitation during the Maunder Minimum is challenging. This does not, however, decrease the potential of regional analysis if the signal is carefully extracted. For example, Fig. 18 shows the winter composite mean response to 30 volcanic eruptions. Although more striking in the second winter, positive North Atlantic Oscillation (NAO)-like patterns, that is, enhanced Icelandic low and Azores high, are seen (Figs. 18a-d). In addition, the spatial patterns of temperature response, warming in northern Europe and northwestern North America and cooling in western Greenland, eastern Canada, the Mediterranean, and northern Africa, are consistent with a typical positive NAO phase during the instrumental period (Figs. 18e and 18f; see also Hurrell 1995). The dynamically consistent patterns between pressure and temperature support the reliability of the analysis. However, the warming in northern Europe is slightly smaller than observations of recent volcanic eruptions (Robock and Mao 1995), and little of the warming is statistically significant. The positive NAO-like pattern following the volcanic eruptions and associated temperature response patterns have been found also in observations (Robock and Mao 1992, 1995; Stenchikov et al. 2002), other model studies (Graf et al. 1993; Stenchikov et al. 2002; Shindell et al. 2001b, 2003, 2004), and reconstructions (Fischer 2003). It is worthy to mention that the stronger NAO response in the second winter than the first winter is in good agreement with reconstructed composite mean response patterns from the 16 large volcanic eruptions during the last 500 years (Fischer 2003).

It has been suggested that tropical stratospheric warming after volcanic eruptions is important in producing a high NAO index because it increases a meridional temperature gradient, which induces a dynamical feedback (Shindell et al. 2001b). This mechanism does not work in our simulations as stratospheric forcing is missing in the experimental setup. Stenchikov et al. (2002) found that tropospheric forcing alone can produce a high NAO index. The geopotential height differences of $\sim 55$ and $\sim 75 \mathrm{~m}$ between centers of action at $500 \mathrm{hPa}$, respectively, in the first and second winters in our simulations are slightly larger than those of Stenchikov et al. (2002) in which $\sim 50 \mathrm{~m}$ is simulated in both winters $(\sim 70 \mathrm{~m}$, only in the first winters with stratospheric forcing). They argue that the reduction of vertically propagating stationary waves associated with the reduced meridional temperature gradient in the troposphere results in the stronger stratospheric polar vortex, which in turn leads to a high NAO index. On the contrary, in our simulations, the stationary wave activity increases, presumably because of the increased land-sea thermal contrast in high latitudes. We attribute the high NAO index to the changes in transient eddy activity and its interaction with mean flow. Activity of transient eddies with periods longer than $\sim 10$ days decreases in the northeastern North Atlantic. Eliassen-Palm flux indicates the reduced westerly deceleration in the upper troposphere although the net effect of the meridional eddy heat transport on the deceleration is controversial (Pfeffer 1987; Hartmann and Lo 1998). Activity of synoptic-scale eddies with periods shorter than $\sim 10$ days increases in the northern North Atlantic along the southern flank of sea ice edge extended to the south after the eruptions. The enhanced baroclinic eddies and westerly acceleration are consis- 
a)

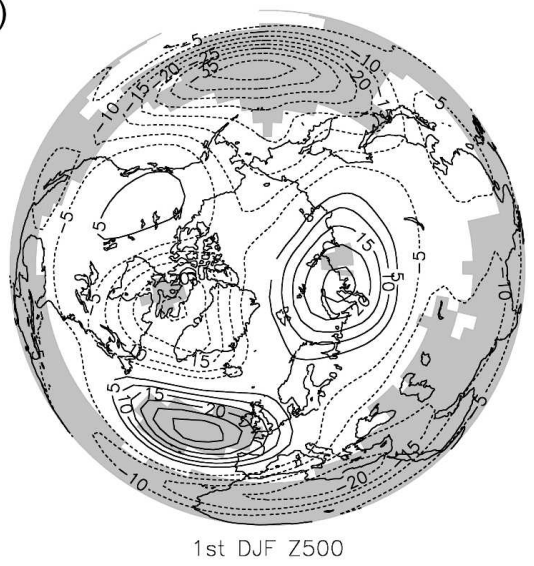

c)

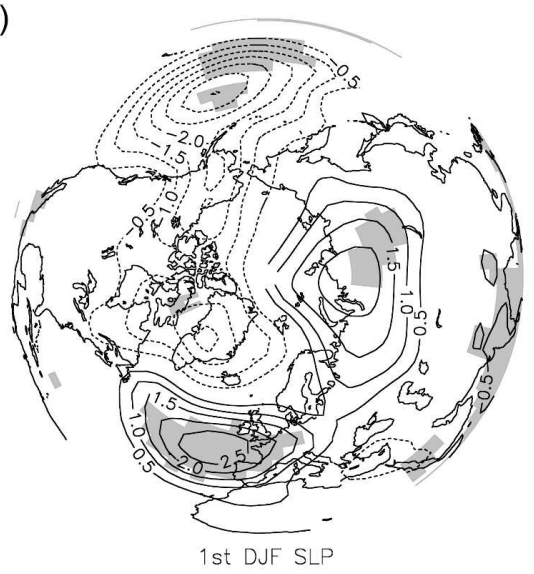

e)

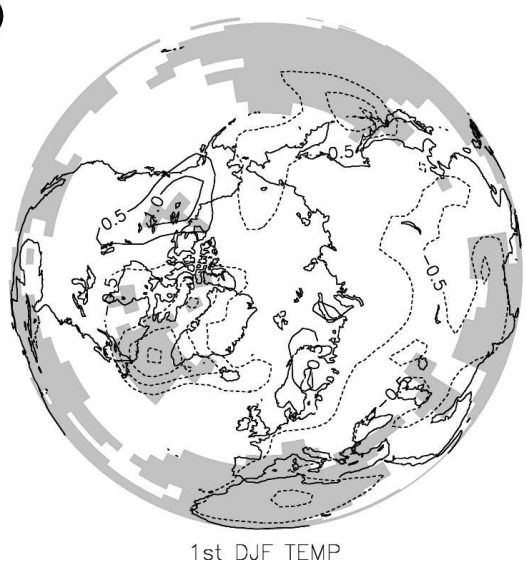

b)

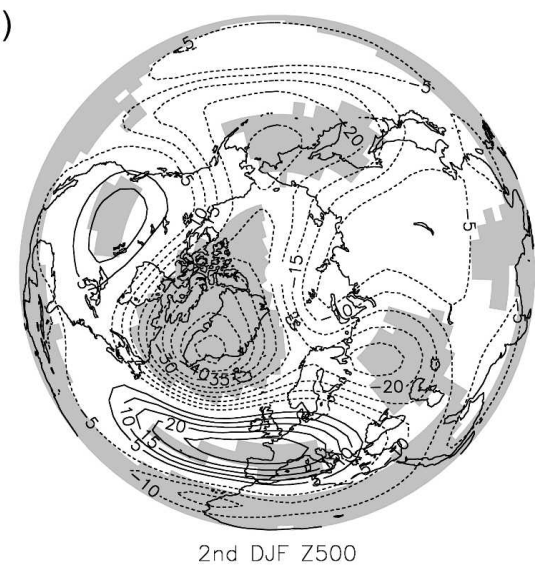

d)

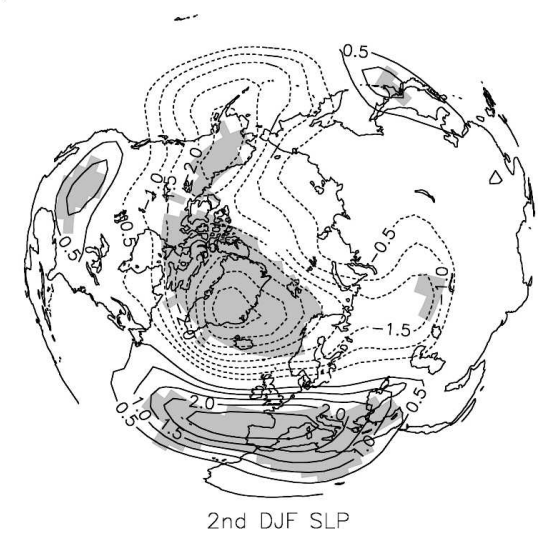

f)

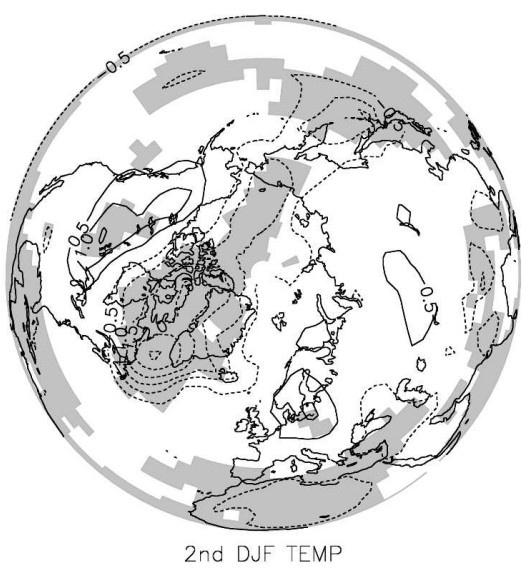

FIG. 18. Composite mean patterns of Northern Hemispheric response to 30 volcanic eruptions in the TMM simulations. Left and right columns represent the first and second winter (Dec-Feb) following the volcanic eruptions, respectively: (a), (b) geopotential height at 500 $\mathrm{hPa}$ with a contour interval (CI) of $5 \mathrm{gpm}$; (c), (d) sea level pressure with $\mathrm{CI}$ of $0.5 \mathrm{hPa}$; and (e), (f) near-surface air temperature with $\mathrm{CI}$ of $0.5^{\circ} \mathrm{C}$. Shadings represent values that are statistically significant at the $10 \%$ level.

tent with the theory of the so-called eddy-driven jet (e.g., Vallis et al. 2004). The westerly jet is, however, counteracted by the reduced meridional temperature gradient in northern Europe more strongly in the first winters. In addition, it is possible that we underestimated the first winter response, as the model exhibits reduced stratospheric meridional temperature gradient without stratospheric forcing. 
Summer composite mean responses to volcanic eruptions, during the volcanic years and in the first and second years after the volcanic eruptions, exhibit globally colder temperatures with enhanced cooling over land (not shown). The cooling signal is statistically significant at many grid points over land, implying that the signal is detectable on grid scales and consistent with Fig. 17.

\section{Discussion}

\section{a. Forcing uncertainty}

In the above analysis, one of the very important factors of uncertainty, the accuracy of solar and volcanic forcing history, is not addressed. The uncertainty in reconstructions of solar forcing arises from the lack of long-term observations, in which satellite measurements are available only since the late 1970s, and poor understanding of physical mechanisms of secular solar variability. This makes it difficult to convert solar magnetic activity to solar irradiance. There is a lack of consensus on interpretation and calibration methods of proxy records. Previous studies have yielded wideranging estimates for the TSI reduction in the Maunder Minimum relative to the present day, that is, $0.1 \%-1 \%$ (Reid 1991; Lean et al. 1992; Baliunas and Jastrow 1993; Hoyt and Schatten 1993; Nesme-Ribes et al. 1993; Zhang et al. 1994; Reid 1997; Solanki and Fligge 1998; Cliver et al. 1998). In addition, it has been suggested that the spectral distribution of solar irradiance changes is important. With spectrally discriminated solar irradiances and consequent changes in stratospheric ozone concentration, Shindell et al. (2001a) simulated enhanced regional winter cooling associated with a low index state of the NAO during the Maunder Minimum. More recently, however, Lean et al. (2002) questioned the validity of the geomagnetic and cosmogenic proxies for solar irradiance and hence reconstructed low solar irradiance during the Maunder Minimum.

The uncertainty in reconstructions of volcanic forcing mainly occurs in extracting signals, from ice core records, representing only the stratospheric sulphate aerosol concentrations associated with climatically significant volcanic eruptions (Robock and Free 1995, 1996; Robock 2000). There are at least two volcanic forcing reconstructions that cover the Maunder Minimum: Crowley (2000) and Robertson et al. (2001). When converted to radiative forcing (E. Zorita 2004, personal communication), volcanic forcing peaks in 1641, 1667, and 1674 are 2-3 times larger in Crowley (2000) than Robertson et al. (2001), and a volcanic forcing peak in 1681 in Crowley (2000) is missing in Robertson et al. (2001). Both reconstructions give a similar magnitude of radiative forcing for the volcanic forcing peak in 1695. In our implementation of the volcanic forcing, stratospheric forcing processes, that is, absorption of near-infrared and infrared radiation by stratospheric sulphate aerosols (Stenchikov et al. 1998), are missing.

Having such a large uncertainty in both solar and volcanic forcing and the absence of stratospheric forcing owing to our experimental setup, it is possible that the model underestimates the response with overestimated forcing (or vice versa). Nevertheless, the agreement with three reconstructions in the Northern Hemisphere temperature changes during the Maunder Minimum provide some comfort to address the issues in extracting the externally forced signal and comparing it with proxy records. In any case, the results presented here should be taken as a conceptual guideline toward a meaningful comparison between model simulations and regional reconstructions.

\section{b. Ensemble size}

The number of ensemble members used in the present study is constrained by the available computational resources. As the number of ensemble members increases $(\geq 30)$, it becomes more statistically meaningful to estimate a confidence interval for the ensemble mean, and we expect that the discrimination of the externally forced signal from the internal variability improves in some cases. Therefore, it is possible that we underestimate the signal-to-noise ratio in our analysis due to the small number of ensemble members. Nevertheless, the proxy records represent only a single realization, and it would be difficult to extract physically meaningful information from the record, if six externally forced model ensemble members are statistically indistinguishable from the internal variability.

\section{Summary and conclusions}

The isolation of the externally forced variability from the internal variability is investigated in the context of the ensemble climate simulations of the Maunder Minimum. Four types of experiments are conducted using the comprehensive climate model: CTRL, SMM, TMM, and STMM simulations. In contrast to the CTRL and SMM simulations, time-varying forcing, including the effect of solar activity and volcanic eruptions, is imposed, and six ensemble members are generated in the TMM simulations. Additionally, a solar-forcing-only simulation, STMM, is also conducted.

The simulated annual Northern Hemisphere and zonal-mean near-surface air temperatures with time- 
varying natural forcing agree well with proxy-based reconstructions on decadal time scales within the uncertainty of the reconstructions. The comparison between model simulations and reconstructions generally becomes more difficult on regional scales, due to both a decreasing externally forced signal level and an increasing internally generated noise level. It is demonstrated that the significant spread of ensemble members is possible even on multidecadal time scales. In our experiments, for example, the externally forced temperature signal averaged over the Maunder Minimum is not clearly detectable in Alaska, Greenland, and northern Europe. We find that temperature exhibits a better signal-to-noise ratio than precipitation in many regions. These results have important implications in searching for suitable proxies and regions in order to reconstruct climatic response to natural forcing in the past. We also find that the externally forced salinity signal is distinguishable on basin scales. This result suggests that there is a large potential in understanding the oceanic response mechanism to natural forcing by optimizing the spatial averaging in capturing the regional signal and characterizing the response patterns in ensemble simulations and reconstructions. In contrast to decadal variability, the volcanically forced signal on shorter time scales is clear on both global and regional scales. The model shows that there is a tendency for the Northern Hemisphere atmosphere to be in the high index state of NAO in winters after volcanic eruptions and that the second winter exhibits the strongest response.

There is a limitation in interpreting solely reconstructed records that represent a single trajectory of the climate system and include both externally forced and internal variability. With this limitation, there remains an issue in verifying the model-simulated natural variability, as it is not possible to remove the possibility that models overestimate the internal variability, and therefore reconstructions fit within the uncertainty range and one might wrongly conclude that they are "consistent." More studies are needed in order to achieve a meaningful comparison between model simulations and regional reconstructions. Reducing the forcing uncertainty is by far the most important issue. Describing the externally forced variability in terms of probability density functions with an ensemble approach and the intermodel comparison would be useful for both understanding of the climatic response to natural forcing and selection of specific time window and regions in focused reconstructions.

Acknowledgments. We are indebted to NCAR for their continuous effort in developing and improving the Community Climate System Model. We greatly appre- ciate technical help from the NCAR Ocean Model Working Group. We are grateful for authors of cited reconstructions in making their data available to the community. We thank Jan Esper for providing tree ring site information, Stefan Gerber for preparing some data, and Anthony Broccoli for useful suggestions on the manuscript. We enjoyed discussions with Erich Fischer. We also thank anonymous reviewers for helpful comments that improved the manuscript. Developers of freely available softwares, SCRIP, NCL and Ferret, are appreciated. This work is supported by the National Centre of Competence in Research (NCCR) Climate funded by the Swiss National Science Foundation. A substantial part of the computations was conducted on IBM Power 4 at the Swiss National Supercomputing Centre (CSCS) in Manno. Urs Beyerle and Stefan Zoller maintained the local computing facility.

\section{REFERENCES}

Baliunas, S., and R. Jastrow, 1993: Evidence on the climate impact of solar variations. Energy, 18, 1285-1295.

Bauer, E., M. Claussen, V. Brovkin, and A. Huenerbein, 2003: Assessing climate forcing of the Earth system for the past millennium. Geophys. Res. Lett., 30, 1276, doi:10.1029/ 2002 GL016639.

Bertrand, C., M.-F. Loutre, M. Crucifix, and A. Berger, 2002: Climate of the last millennium: A sensitivity study. Tellus, 54A, 221-244.

Blunier, T., J. Chappellas, J. Schwander, B. Stouffer, and D. Raynaud, 1995: Variations in atmospheric methane concentration during the Holocene epoch. Nature, 374, 46-49.

Bradley, R. S., K. R. Briffa, J. Cole, M. K. Hughes, and T. J. Osborn, 2003: The climate of the last millennium. Paleoclimate, Global Change and the Future, K. Alverson, R. S. Bradley, and T. F. Pedersen, Eds., Springer-Verlag, 105-141.

Briffa, K. R., P. D. Jones, F. H. Schweingruber, and T. J. Osborn, 1998: Influence of volcanic eruptions on Northern Hemisphere summer temperature over the past 600 years. Nature, 393, 450-455.

Broccoli, A. J., K. W. Dixon, T. L. Delworth, T. R. Knutson, R. J. Stouffer, and F. Zeng, 2003: Twentieth-century temperature and precipitation trends in ensemble climate simulations including natural and anthropogenic forcing. J. Geophys. Res., 108, 4798, doi:10.1029/2003JD003812.

Bryan, K., 1984: Accelerating the convergence to equilibrium of ocean-climate models. J. Phys. Oceanogr., 14, 666-673.

Cliver, E. W., V. Boriakoff, and J. Feynman, 1998: Solar variability and climate change: Geomagnetic as index and global surface temperature. Geophys. Res. Lett., 25, 1035-1038.

Cook, E. R., C. A. Woodhouse, C. M. Eakin, D. M. Meko, and D. W. Stahle, 2004: Long-term aridity changes in the western United States. Science, 306, 1015-1018.

Crowley, T. J., 2000: Causes of climate change over the past 1000 years. Science, 289, 270-277.

Cubasch, U., and Coauthors, 2001: Projections of future climate change. Climate Change 2001: The Scientific Basis, J. T. Houghton et al., Eds., Cambridge University Press, 525-582.

Dunbar, R. B., G. M. Wellington, M. W. Colgan, and P. W. Glynn, 1994: Eastern Pacific sea surface temperature since 
1600 A.D.: The $\delta^{18} \mathrm{O}$ record of climate variability in Galápagos corals. Paleoceanography, 9, 291-315.

Eddy, J. A., 1976: The Maunder Minimum. Science, 192, 1189 1202.

Esper, J., E. R. Cook, and F. H. Schweingruber, 2002: Lowfrequency signals in long tree-ring chronologies for reconstructing past temperature variability. Science, 295, 22502253.

Fischer, E., 2003: Regional and seasonal impact of volcanic eruptions on European climate over the last centuries. Diploma thesis, University of Bern, $115 \mathrm{pp}$.

Flückiger, J., E. Monnin, B. Stauffer, J. Schwander, T. F. Stocker, J. Chappellaz, D. Raynaud, and J.-M. Barnola, 2002: Highresolution Holocene $\mathrm{N}_{2} \mathrm{O}$ ice core record and its relationship with $\mathrm{CH}_{4}$ and $\mathrm{CO}_{2}$. Global Biogeochem. Cycles, 16,1010, doi:10.1029/2001GB001417.

Forest, C. E., P. H. Stone, A. P. Sokolov, M. R. Allen, and M. D. Webster, 2002: Quantifying uncertainties in climate system properties with the use of recent climate observations. Science, 295, 113-117.

Free, M., and A. Robock, 1999: Global warming in the context of the Little Ice Age. J. Geophys. Res., 104, 19 057-19 070.

Gerber, S., F. Joos, P. Brügger, T. F. Stocker, M. E. Mann, S. Sitch, and M. Scholze, 2003: Constraining temperature variations over the last millenium by comparing simulated and observed atmospheric $\mathrm{CO}_{2}$. Climate Dyn., 20, 281-299.

Giorgi, F., and R. Francisco, 2000: Uncertainties in regional climate change prediction: A regional analysis of ensemble simulations with the HADCM2 coupled AOGCM. Climate Dyn., 16, 169-182.

Graf, H. F., I. Kirchner, A. Robock, and I. Schult, 1993: Pinatubo eruption winter climate effects: Model versus observations. Climate Dyn., 9, 81-93.

Hartmann, D. L., and F. Lo, 1998: Wave-driven zonal flow vacillation in the Southern Hemisphere. J. Atmos. Sci., 55, 1303 1315.

Hendy, E. J., M. K. Gagan, C. A. Alibert, M. T. McCulloch, J. M. Lough, and P. J. Isdale, 2002: Abrupt decrease in tropical Pacific sea surface salinity at end of Little Ice Age. Science, 295, 1511-1514.

Hoyt, D. V., and K. H. Schatten, 1993: A discussion of plausible solar irradiance variations, 1700-1992. J. Geophys. Res., 98, 18 895-18 906.

Hurrell, J. W., 1995: Decadal trends in the North Atlantic Oscillation: Regional temperatures and precipitation. Science, 269, 676-679.

Jones, P. D., K. R. Briffa, T. P. Barnett, and S. F. B. Tett, 1998: High-resolution palaeoclimatic records for the last millennium: Interpretation, integration and comparison with general circulation model control-run temperatures. Holocene, $\mathbf{8}$, $455-471$.

— - T. J. Osborn, and K. R. Briffa, 2001: The evolution of climate over the last millennium. Science, 292, 662-667.

Keigwin, L. D., 1996: The Little Ice Age and Medieval Warm Period in the Sargasso Sea. Science, 274, 1504-1508.

— rentian Fan on interannual to millennial time scales. Science, 286, 520-523.

Kiehl, J. T., and P. R. Gent, 2004: The Community Climate System Model, version 2. J. Climate, 17, 3666-3682.

Knutti, R., T. F. Stocker, F. Joos, and G.-K. Plattner, 2002: Constraints on radiative forcing and future climate change from observations and climate model ensembles. Nature, 416, 719723.

Lean, J., A. Skumanich, and O. White, 1992: Estimating the sun's radiative output during the Maunder Minimum. Geophys. Res. Lett., 19, 1591-1594.

- J. Beer, and R. Bradley, 1995: Reconstruction of solar irradiance since 1610: Implications for climate change. Geophys. Res. Lett., 22, 3195-3198.

_, Y.-M. Wang, and N. R. Sheeley Jr., 2002: The effect of increasing solar activity on the Sun's total and open magnetic flux during multiple cycles: Implications for solar forcing of climate. Geophys. Res. Lett., 29, 2224, doi:10.1029/2002GL015880.

Lorenz, E. N., 1963: Deterministic nonperiodic flow. J. Atmos. Sci., 20, 130-148.

Luterbacher, J., and Coauthors, 2002: Reconstruction of sea level pressure fields over the Eastern North Atlantic and Europe back to 1500 . Climate Dyn., 18, 545-561.

- D. Dietrich, E. Xoplaki, M. Grosjean, and H. Wanner, 2004: European seasonal and annual temperature variability, trends, and extremes since 1500. Science, 303, 1499-1503.

Mann, M. E., R. S. Bradley, and M. K. Hughes, 1999: Northern Hemisphere temperatures during the past millennium: Inferences, uncertainties, and limitations. Geophys. Res. Lett., 26, 759-762.

— M. K. Hughes, E. R. Cook, and J. Esper, 2002: Tree-ring chronologies and climate variability. Science, 296, 848-849.

— late-20th century warmth. Eos, Trans. Amer. Geophys. Union, 84, 256.

Mitchell, J. F. B., D. J. Karoly, G. C. Hegerl, F. W. Zwiers, M. R. Allen, and J. Marengo, 2001: Detection of climate change and attribution of causes. Climate Change 2001: The Scientific Basis, J. T. Houghton et al., Eds., Cambridge University Press, 695-738.

Moberg, A., D. M. Sonechkin, K. Holmgren, N. M. Datsenko, and W. Karlén, 2005: Highly variable Northern Hemisphere temperatures reconstructed from low- and high-resolution proxy data. Nature, 433, 613-617.

Nesme-Ribes, E., E. N. Ferreira, R. Sadourny, H. L. Treut, and Z. X. Li, 1993: Solar dynamics and its impact on solar irradiance and the terrestrial climate. J. Geophys. Res., 98, $18923-$ 18935.

Palmer, T. N., 1998: Nonlinear dynamics and climate change: Rossby's legacy. Bull. Amer. Meteor. Soc., 79, 1411-1423.

, 1999: A nonlinear dynamical perspective on climate prediction. J. Climate, 12, 575-591.

Pfeffer, R. L., 1987: Comparison of conventional and transformed Eulerian diagnostics in the troposphere. Quart. J. Roy. Meteor. Soc., 113, 237-254.

Ramaswamy, V., and Coauthors, 2001: Radiative forcing of climate change. Climate Change 2001: The Scientific Basis, J. T. Houghton et al., Eds., Cambridge University Press, 349-416.

Reid, G. C., 1991: Solar total irradiance variations and the global sea surface temperature record. J. Geophys. Res., 96, 28352844.

_ 1997: Solar forcing of global climate change since the mid17th century. Climate Change, 37, 391-405.

Renold, M., U. Beyerle, C. C. Raible, R. Knutti, and T. F. Stocker, 2004: Climate modeling with a Linux cluster. Eos, Trans. Amer. Geophys. Union, 85, 290.

Robertson, A., and Coauthors, 2001: Hypothesized climate forcing time series for the last 500 years. J. Geophys. Res., 106, $14783-14803$ 
Robock, A., 1978a: Internally and externally caused climate change. J. Atmos. Sci., 35, 1111-1122.

— 1978b: The "Little Ice Age": Northern Hemisphere average observations and model calculations. Science, 206, 1402-1404.

_ 2000: Volcanic eruptions and climate. Rev. Geophys., 38, 191-219.

_ tions. Geophys. Res. Lett., 19, 2405-2408.

— for Space Studies three-dimensional model simulations. $J$. Climate, 7, 44-55.

— , and M. P. Free, 1995: Ice cores as an index of global volcanism from 1850 to the present. J. Geophys. Res., 100, 11549 11567.

— observations. J. Climate, 8, 1086-1103.

— , and M. P. Free, 1996: The volcanic record in ice cores for the past 2000 years. Climatic Variations and Forcing Mechanisms of the Last 2000 Years, P. D. Jones, R. S. Bradley, and J. Jouzel, Eds., Springer-Verlag, 533-546.

Shindell, D. T., G. A. Schmidt, M. E. Mann, D. Rind, and A. Waple, 2001a: Solar forcing of regional climate change during the Maunder Minimum. Science, 294, 2149-2152.

,,-- R. L. Miller, and D. Rind, 2001b: Northern Hemisphere winter climate response to greenhouse gas, ozone, solar, and volcanic forcing. J. Geophys. Res., 106, 7193-7210.

,,--- , and M. E. Mann, 2003: Volcanic and solar forcing of climate change during the preindustrial era. J. Climate, 16, 4094-4107.

- - — M. E. Mann, and G. Faluvegi, 2004: Dynamic winter climate response to large tropical volcanic eruptions since 1600. J. Geophys. Res., 109, D05104, doi:10.1029/2003JD004151.

Siegenthaler, U., and Coauthors, 2005: Supporting evidence from the EPICA Dronning Maud ice core for atmospheric $\mathrm{CO}_{2}$ changes during the past millenium. Tellus, 57B, 51-57.
Soden, B. J., R. T. Wetherald, G. L. Stenchikov, and A. Robock, 2002: Global cooling after the eruption of Mount Pinatubo: A test of climate feedback by water vapor. Science, 296, 727730 .

Solanki, S. K., and M. Fligge, 1998: Solar irradiance since 1874 revisited. Geophys. Res. Lett., 25, 341-344.

Stenchikov, G. L., I. Kirchner, A. Robock, H.-F. Graf, J. C. Antuña, R. G. Grainger, A. Lambert, and L. Thomason, 1998: Radiative forcing from the 1991 Mount Pinatubo volcanic eruption. J. Geophys. Res., 103, 13 837-13 857.

—, A. Robock, V. Ramaswamy, M. D. Schwarzkopf, K. Hamilton, and S. Ramachandran, 2002: Arctic Oscillation response to the 1991 Mount Pinatubo eruption: Effects of volcanic aerosols and ozone depletion. J. Geophys. Res., 107, 4803, doi:10.1029/2002JD002090.

Vallis, G. K., E. P. Gerber, P. J. Kushner, and B. A. Cash, 2004: A mechanism and simple dynamical model of the North Atlantic Oscillation and annular modes. J. Atmos. Sci., 61, 264-280.

Zaucker, F., and W. S. Broecker, 1992: The influence of atmospheric moisture transport on the fresh water balance of the Atlantic drainage basin: General circulation model simulations and observations. J. Geophys. Res., 97, 2765-2773.

Zhang, Q., W. H. Soon, S. L. Baliunas, G. W. Lockwood, B. A. Skiff, and R. R. Radick, 1994: A method of determining possible brightness variations of the sun in past centuries from observations of solar-type stars. Astrophys. J., 427, L111L114.

Zorita, E., H. von Storch, F. Gonzalez-Rouco, U. Cubasch, J. Luterbacher, S. Legutke, I. Fischer-Bruns, and U. Schlese, 2004: Climate evolution in the last five centuries simulated by an atmosphere-ocean model: Global temperatures, the North Atlantic Oscillation and the late Maunder Minimum. Meteor. Z., 13, 271-289. 